\title{
Explaining the Declining Energy Intensity of the U.S. Economy
}

\author{
Ian Sue Wing* \\ Center for Energy \& Environmental Studies and Geography Department, Boston University \\ and \\ Joint Program on the Science \& Policy of Global Change, MIT
}

\begin{abstract}
This paper reconciles conflicting explanations for the decline in U.S. energy intensity over the last 40 years of the $20^{\text {th }}$ century. Decomposing changes in the energy-GDP ratio into shifts in the structure of sectoral composition and adjustments in the efficiency of energy use within individual industries reveals that while inter-industry structural change was the principal driver of the observed decline in aggregate energy intensity, intra-industry efficiency improvements played a more important role in the post-1980 period. Econometric results attribute this phenomenon to adjustments in quasi-fixed inputs-particularly vehicle stocks, and disembodied autonomous technological progress, and show that price-induced substitution of variable inputs generated transitory energy savings, while innovation induced by energy prices had only a minor impact.
\end{abstract}

JEL classification: Q3, Q4

\footnotetext{
*Rm. 461, 675 Commonwealth Ave., Boston MA 02215. Phone: (617) 353-5741. Email: isw@ bu.edu. This paper has benefited from valuable contributions by Richard Eckaus, as well as discussions with Gilbert Metcalf, M. Scott Taylor, Tim Considine, Karen Fisher Vanden David Popp, Fred Joutz, Peter Wilcoxen and participants at the IAEE sessions in the annual meetings of the Allied Social Science Association and the Western Economic Association. Thanks are also due to the editor and two anonymous referees for very helpful comments and suggestions. The author is solely responsible for errors and omissions. This research was supported by U.S. Department of Energy Office of Science (BER) Grants Nos. DE-FG02-02ER63484 and DE-FG02-06ER64204.
} 


\section{Introduction}

This paper investigates the sources of the decline in the energy intensity of the U.S. economy during the period 1958-2000, in particular the impact of technological change and its importance relative to that of other influences. This issue, with which economists have wrestled for three decades, is again a focus of interest, stimulated by recent energy price increases and proposals to reduce the greenhouse gas (GHG) emissions associated with fossil fuel use.

The OPEC oil price shocks of the 1970s and their adverse economic consequences generated a groundswell of empirical research on the reaction of technology to such price changes. However, questions remain about both the sign and magnitude of the effects of energy prices on innovation, and the follow-on impact of technological change on the intensity of energy use. Concern has also arisen over the economic impacts of measures to deal with the problem of climate change, particularly energy price increases induced by limits on carbon dioxide emissions from fossil-fuel combustion. Of particular interest is the potential for induced technical change (ITC), whereby regulations to reduce emissions stimulate innovation which saves energy and reduces emissions. ${ }^{1}$ Finally, apprehension over the economic consequences of the current high global energy prices has re-kindled interest in the robustness of U.S. productivity growth to price shocks. ${ }^{2}$

In the present paper I focus on the relationship between energy prices and energy productivity, or, more specifically, its inverse-energy intensity. Figure 1 illustrates the historical trends of these variables in the U.S. economy. The most striking feature is the

\footnotetext{
${ }^{1}$ Energy-saving technological change is frequently adduced as the saving grace that will moderate the costs of abating $\mathrm{CO}_{2}$ emissions over the long time-horizon on which emission limits are anticipated to bind. Sue Wing (2006) elucidates the mechanisms by which changes in relative prices influence the rate and direction of firms' innovation.

${ }^{2}$ e.g., "Energy and the Economy", remarks by Federal Reserve Chairman Ben S. Bernanke before the Economic Club of Chicago, Chicago, IL, 15 June, 2006 (http://www.federalreserve.gov/Boarddocs/speeches/2006/200606152/default.htm).
} 
sustained reduction in the energy-GDP ratio, whose steepest decline occurs in the period 19741986, during which energy prices first jumped due to the OPEC oil shocks, and then collapsed. I consider three channels through which prices influence energy intensity: (1) input substitutionthe direct effect of increases in energy's relative price on the mix of inputs to production, holding the state of technology constant, (2) innovation-resulting from both the secular progress of scientific advance and the inducement effects of high energy prices, and (3) changes in the mix of industries in the economy. Despite much prior work scrutinizing each of these mechanisms, the empirical estimates developed by different studies are for the most part incommensurate. The objective here is to develop comprehensive and comparable estimates for the magnitudes of these influences.

The first comprehensive econometric estimates of the substitution effects of the energy price shocks of the 1970s were developed by Jorgenson and Fraumeni (1981) and Jorgenson (1984). The principal advantage of this work, which was conducted at the industry level, is its coverage of the entire supply side of the U.S. economy. Most controversial have been its estimates of the effects of disembodied technical progress on energy demand, which indicate that the majority of U.S. industries exhibit an energy-using bias of innovation. Not only is this result seemingly at odds with the observed decline in energy intensity, it is inconsistent with the assumption of aggregate energy-saving technical change (the autonomous energy efficiency improvement, or AEEI) which underpins most of the simulations of future energy use and $\mathrm{CO}_{2}$ emissions. ${ }^{3}$ Indeed, on the basis of this result Hogan and Jorgenson (1991) argue that the AEEI might actually be negative!

\footnotetext{
${ }^{3}$ As discussed by Hogan (1990), Manne and Richels (1992) and Williams (1990), the AEEI is a secular trend reflecting the technologically-motivated rate of reduction in the demand for energy that, without any directed effort, decreases the amounts of $\mathrm{CO}_{2}$-emitting fossil fuel necessary for any given level of economic output. Its first documented use is Edmonds and Reilly (1985), who cite the historical decline in the energy intensity of GDP with
} 
A potential resolution to this paradox lies in the fact that Jorgenson's findings were generated using a dataset which ends 1979, when energy prices were at their peak, just prior to the sharp decline in the energy-GDP ratio. Thus, a key theme of this paper is the question of whether there is still evidence for widespread disembodied energy-using innovation over a longer sample which encompasses the period in Figure 1 (1958-2000).

The bias of technical change with respect to energy is also ripe for re-examination given results from more recent investigations of ITC at the micro level, which suggest that innovation has been energy-saving in character, and has, moreover, been induced by energy prices. Using patent data, Popp (2002) demonstrates that the energy price shocks of the 1970s induced a substantial amount of energy-saving innovation. Complementary work by Newell et al (1999) finds that energy prices induced energy-saving changes in the characteristics of residential capital. $^{4}$

However, there is continuing debate over the magnitude of the aggregate impact of these phenomena, with two investigations of its effect on energy use manufacturing sectors reaching very different conclusions. Popp (2001) estimates that one third of the reduction in manufacturing industries' energy-output ratios to the effects of energy-related knowledge embodied in patents. By contrast, Linn (2006) estimates that adoption of energy-saving technology by new manufacturing plants in response to a ten-percent rise in energy prices resulted in only a one-percent reduction in energy demand. These findings raise additional questions about the sources of intensity change: first, how much has energy price-induced

\footnotetext{
increasing economic development as justification for a declining coefficient on energy input. They construct a simulation model that incorporates an increasing index of energy-saving technology, whose inverse is applied as an attenuation factor to the model's fuels demand functions. This trick is still employed in the majority of climate policy models.

${ }^{4}$ Newell et al (1999) find that energy prices and regulatory stimuli positively affect the energy-efficiency characteristics of consumer durables for heating and cooling. Popp (2002) finds that the propensity to patent in energy technology fields was significantly increased by rising energy prices in the 1970s.
} 
innovation altered the characteristics of non-residential capital, and second, what has been the follow-on impact on aggregate energy intensity.

To address the latter question it is necessary to understand how the effects of technology on energy demand aggregate up to the level of the macroeconomy. This issue is the focus of decomposition studies (see, e.g., the survey by Ang and Zhang, 2000) which combine industry and macroeconomic data to isolate how changes in the mix of economic sectors have affected the evolution of the energy-GDP ratio. These have tended to attribute much of the decline in intensity to changes in the composition of output (e.g., Rose and Chen 1991), particularly among manufacturing industries (Hirst et al 1983; Schipper et al 1990). Motivated by these findings, the paper investigates whether structural change was a more or less important contributor to aggregate energy intensity than substitution or innovation.

To sort out the contributions of these various influences at the aggregate level in a comprehensive and consistent manner, I employ a synthesis of the methodological approaches outlined above. Following Jorgenson's lead, I maximize sectoral coverage by accounting for the sources of change in energy intensity within 35 economic sectors at the approximate 2-digit level of aggregation. To investigate the importance of changes in the composition of industries' capital relative to substitution and innovation, I develop an econometric model of dynamic factor demands which incorporates a broad array of quasi-fixed inputs, and perform estimations using a unique dataset for the period 1958-2000 which updates Jorgenson's results across the full range of producing sectors in the economy. Finally, the resulting sectoral estimates are aggregated using a decomposition technique, thereby reconciling the apparent differences between energy intensity trends at the micro and macro levels of the economy. 
Embodied in this approach are two key innovations. The first is the extension of Popp's (2001) econometric model of ITC to incorporate a proxy for the stock of energy-saving knowledge which is based solely on energy price data. This permits the impacts of exogenous and induced technical progress on industries' demands for energy to be separately identified. The second is the development of a simple decomposition scheme which attributes changes in aggregate energy intensity to the influence of changes in the mix of industries and factors which occur within industries. This scheme provides a mechanism for aggregating the econometric estimates across sectors to yield comparable measures of the macroeconomic impacts of substitution, technical progress and capital accumulation.

I find that change in the sectoral composition of the economy is the main driver of the decline in aggregate energy intensity over the sample period. Of the changes that occur within industries, disembodied exogenous technical progress is the predominant energy-saving influence, with shifts in the composition of capital coming a close second. The influence of substitution is mixed. It had a substantial energy-saving effect during the period of high energy prices in the 1970s and 80s, but was slightly energy using over the remainder of the sample period. Finally, disembodied induced technical change was energy saving as well, but of the factors considered it has the smallest impact, which only arises in the aftermath of the energy price shocks.

The plan of the paper is as follows. Section 2 develops an econometric model of producer behavior which provides a natural way to account for the sources of change in the energy intensity of economic sectors. There I also outline the decomposition procedure which facilitates consistent aggregation of the sectoral econometric estimates. Section 3 describes the data and the estimation technique. In Section 4 presents and discusses the econometric estimates of the 
sources of change in energy demand within the different industries. Section 5 presents the results of the decomposition analysis, which aggregates over industries to elucidate the contributions of their constituent sources of change to the evolution of the energy-GDP ratio. Section 6 concludes with a discussion of caveats and future research needs in this area.

\section{Modeling The Sources of Change in Energy Demand}

\subsection{An econometric model of producer behavior}

The economy is modeled as a collection of industries, indexed by $i=1, \ldots, N$. In each industry there is a representative producer with a short-run restricted variable cost function (RVCF), $G_{i}\left[\mathbf{P}_{i}, \mathbf{X}_{i}, \dot{\mathbf{X}}_{i}, Y_{i}, t\right]$, in which $\mathbf{P}_{i}$ is a vector of variable input prices, $\mathbf{X}_{i}$ is the level and $\dot{\mathbf{X}}_{i}$ is the change in the vector of quasi-fixed inputs to production, $Y_{i}$ is the level of output and $t$ is time. Each producer faces the problem of choosing the trajectory of quasi-fixed inputs to minimize the present discounted value of costs:

$$
\min _{\mathbf{x}_{i}, \dot{\mathbf{x}}_{i}} \int_{0}^{\infty} e^{-r t}\left\{G_{i}\left[\mathbf{P}_{i}, \mathbf{X}_{i}, \dot{\mathbf{X}}_{i}, Y_{i}, t\right]+\mathbf{u}_{i} \cdot \mathbf{x}_{i}\right\} d t
$$

where $r$ is the interest rate, $\mathbf{u}_{i}=r \mathbf{a}_{i}+\mathbf{d} \cdot \mathbf{a}_{i}$ is the user cost of the vector of quasi-fixed inputs, $\mathbf{a}_{i}$ is the vector of their normalized acquisition (asset) prices, and $\mathbf{d}$ is the vector of asset-specific rates of depreciation. Berndt, Morrison and Watkins (1981) show that in the stationary equilibrium where $\dot{\mathbf{X}}_{i}=0$ and the quasi-fixed inputs have fully adjusted to their long-run optimal levels, $\dot{\mathbf{X}}_{i}^{*}$, the solution to the problem in eq. (1) is given by the equilibrium condition:

$$
-\frac{\partial G_{i}\left[\mathbf{P}_{i}, \mathbf{X}_{i}^{*}\right]}{\partial \mathbf{X}_{i}}=\mathbf{u}_{i}+r \frac{\partial G_{i}\left[\mathbf{P}_{i}, \mathbf{X}_{i}^{*}\right]}{\partial \dot{\mathbf{X}}_{i}}
$$


Following Berndt, Morrison and Watkins (1981), Watkins and Berndt (1992), and especially Popp (2001), industry $i$ 's normalized RVCF is specified using a quadratic approximation for $G$ :

$$
\begin{aligned}
G_{i} & =L_{i}+\frac{P_{E i}}{P_{L i}} E_{i}+\frac{P_{M i}}{P_{L i}} M_{i}=L_{i}+p_{E i} E_{i}+p_{M i} M_{i} \\
& =Y_{i}\left[\alpha_{0 i}+\alpha_{0 T i} t+\sum_{v} \alpha_{v i} p_{v i}+\frac{1}{2} \sum_{v} \alpha_{v v i} p_{v i}^{2}+\sum_{v} p_{v i} t+\sum_{v} \sum_{j \neq v} \alpha_{v j i} p_{v i} p_{j i}\right] \\
& +\sum_{k} \alpha_{k i} X_{k i,-1}+\frac{1}{2} \sum_{k} \alpha_{k k i} \frac{X_{k i,-1}^{2}}{Y_{i}}+\sum_{k} \alpha_{k T i} X_{k i,-1} t+\sum_{k} \sum_{v} \alpha_{k v i} X_{k i,-1} p_{v i} \\
& +\sum_{k} \beta_{k i} \dot{X}_{k i,-1}+\frac{1}{2} \sum_{k} \beta_{k k i} \frac{\dot{X}_{k i,-1}^{2}}{Y_{i}}+\sum_{k} \beta_{k T i} \dot{X}_{k i,-1} t+\sum_{k} \sum_{v} \beta_{k v i} \dot{X}_{k i,-1} p_{v i}+\sum_{k} \gamma_{k k i} \frac{X_{k i,-1} \dot{X}_{k i,-1}}{Y_{i}}
\end{aligned}
$$

In this expression, variable inputs are denoted by the index $v^{\prime}=\{$ labor $(L)$, energy $(E)$, materials $(M)\}$, the prices of which are given by $P_{v^{\prime} i}$. The prices series used in the regressions below are normalized by the wage: $p_{v i}(v=\{E, M\})$. The variables $X_{k i,-1}$ and $\dot{X}_{k i,-1}$ are the levels and changes in $k$ classes of quasi-fixed asset stocks, lagged one period. Henceforth I use the lower case forms of these variables to denote their input intensities: $x_{k i}=X_{k i,-1} / Y_{i}$ and $\dot{x}_{k i}=\dot{X}_{k i,-1} / Y_{i}$. The variable $t$ is a time trend, which is designed to capture the effects of exogenous technical progress on the demands for variable inputs. The objective is to estimate the coefficients $\alpha, \beta$ and $\gamma$.

Watkins and Berndt (1992) note the difficulty of empirically distinguishing the effects of scale and innovation in eq. (3). The estimated coefficients often imply long-run increasing returns to scale accompanied by technological retrogression, despite the plausibility and empirical evidence for long-run constant returns to scale (LRCRTS) at the industry level. My identifying assumption is to impose LRCRTS by employing the net investment version of their model. 
Industry $i$ 's internal costs of adjustment, $A_{i}$, are represented by all the terms in the variable cost function involving changes in quasi-fixed inputs, $\dot{X}_{k i}$. When normalized by the level of output, adjustment costs are:

$$
a_{i}=\frac{A_{i}}{Y_{i}}=\sum_{k} \beta_{k i} \dot{x}_{k i}+\frac{1}{2} \sum_{k} \beta_{k k i} \dot{x}_{k i}^{2}+\sum_{k} \beta_{k t i} \dot{x}_{k i} t+\sum_{k} \sum_{v} \beta_{k v i} \dot{x}_{k i} p_{v i}+\sum_{k} \gamma_{k k i} x_{k i} \dot{x}_{k i}
$$

When the stocks of quasi-fixed inputs have fully adjusted to their optimal intensities, $x_{k i}^{*}$, both the change in the levels of these stocks, $\dot{x}_{k i}^{*}$, and the marginal unit adjustment costs must be zero. We therefore have:

$$
\left.\frac{\partial a_{i}}{\partial \dot{x}_{k i}}\right|_{x_{k i}=x_{k i}^{*}, \dot{x}_{k i}=0}=\sum_{k} \beta_{k i}+\sum_{k} \beta_{k t i} t+\sum_{k} \sum_{v} \beta_{k v i} p_{v i}+\sum_{k} \gamma_{k k i} x_{k i}^{*}=0
$$

which implies the following restriction on the parameters:

$$
\beta_{k i}=\beta_{k t i}=\beta_{k v i}=\gamma_{k k i}=0 .
$$

By Shepard's Lemma, the optimal conditional short-run input demands are given by the derivatives of $G_{i}$ with respect to the normalized prices of the variable inputs. Imposing LRCRTS using eq. (5) then yields conditional input demand functions for energy and materials:

$$
\begin{aligned}
& e_{i}=E_{i} / Y_{i}=\alpha_{E i}+\alpha_{E E i} p_{E i}+\alpha_{E M i} p_{M i}+\alpha_{E T i} t+\sum_{k} \alpha_{E k i} x_{k i} \\
& m_{i}=M_{i} / Y_{i}=\alpha_{M i}+\alpha_{E M i} p_{E i}+\alpha_{M M i} p_{M i}+\alpha_{M T i} t+\sum_{k} \alpha_{M k i} x_{k i} .
\end{aligned}
$$

The associated conditional demand for labor is derived as a residual from eq. (3):

$$
\begin{aligned}
l_{i}= & L_{i} / Y_{i}=G_{i} / Y_{i}-p_{E i} e_{i}-p_{M i} m_{i} \\
= & \alpha_{0 i}+\alpha_{0 T i} t-\frac{1}{2}\left(\alpha_{E E i} p_{E i, t}^{2}+2 \alpha_{E M i} p_{E i, t} p_{M i, t}+\alpha_{M M i} p_{M i, t}^{2}\right) \\
& +\sum_{k} \alpha_{k i} x_{k i}+\frac{1}{2} \sum_{k} \alpha_{k k i} x_{k i}^{2}+\sum_{k} \alpha_{k T i} x_{k i} t+\frac{1}{2} \sum_{k} \beta_{k k i} \dot{x}_{k i}^{2} .
\end{aligned}
$$


Finally, it is useful to derive the long-run equilibrium effect of quasi-fixed inputs on variable cost, which is found by differentiating (3) with respect to $X_{k i}$ :

$$
\left.\frac{\partial G_{i}}{\partial X_{k i}}\right|_{X_{k i}=X_{k i}^{*}, \dot{X}_{k i}=0}=\alpha_{k i}+\alpha_{k k i} x_{k i}^{*}+\alpha_{k t i} t+\sum_{v} \alpha_{k v i} p_{v i}
$$

This expression, along with eq. (4), implies that the equilibrium condition in (2) may be solved for the optimal quantity of quasi-fixed inputs per unit of output:

$$
x_{k i}^{*}=-\left(\alpha_{k i}+\alpha_{k T i} t+\sum_{v} \alpha_{k v i} p_{v i}+u_{k i}\right) / \alpha_{k k i}
$$

Eqs. (6)-(8) form my econometric model of producer behavior, in which the coefficients on the prices reflect the impact of substitution among variable inputs, those on the quasi-fixed stocks give the effects of changes in the level and composition of capital, and those on the time trends proxy for the influence of technological progress on the demand for each input. The strength of this model is its ability to distinguish between the effects on energy demand of shortrun movements in variable input prices and long-run adjustments of a range of different quasifixed inputs. The marked variation among different assets in their service lives and energy-using characteristics suggests that the differential accumulation of quasi-fixed inputs is likely to be the key diver of persistence in industries' energy demand. In addition, Newell et al's (1999) results suggest that the capitalization of new technology into successive generations of assets is likely to be an important factor which mitigates this upward trend. This econometric framework gives us the ability to separately identify the impacts of both processes on industries' demand for energy.

The model's disadvantage is its limited capability to identify the influence of priceinduced energy-saving innovation. Linn (2006) identifies this effect using the difference between the energy intensities of incumbent and entrant manufacturing plants, while Popp (2001) uses the cumulated stocks of energy patents in each industry as direct proxy for the intangible output of 
innovation. The latter approach is attractive because it is the equivalent of specifying a stock of disembodied energy-saving knowledge as a quasi-fixed input in the model, but the absence of data on the use of patents by industry prevented me from implementing this scheme directly. ${ }^{5}$

The first novel aspect of this study is its use of the trick of cumulating energy price increases as the proxy for the stock of knowledge. The fundamental assumption in this regard is that energy price shocks stimulate the creation of energy-saving ideas and process and product designs. The latter make up a stock of intangible capital whose effect on energy demand is mediated by three forces: persistence in the energy-saving effect of price shocks due to the durability of inventions and ideas, declining energy-saving effects with the passage of time due to the obsolescence of these factors, and lags in the onset of induced energy savings due to the time necessary to conduct research and innovation, and to diffuse the resulting innovations among the firms in each industry.

I model these forces in the same way as Popp (2001), representing inducement via energy price increases instead of patent counts. ${ }^{6}$ Following his eq. (3), my proxy for the stock of disembodied energy-saving knowledge in year $t\left(X_{\text {Knowledge, } i, t}\right)$, is the sum of past energy price increases, $\pi_{E i}=100 \times \max \left(0, \Delta p_{E i}\right){ }^{7}$ weighted by the time-dependent influences of knowledge decay and diffusion:

$$
X_{\text {Knowledge }, i t}=\int_{0}^{\infty} \pi_{E i, s} \exp \left(-\delta_{1 i} s\right)\left[1-\exp \left(-\delta_{2 i}(s+1)\right)\right] d s .
$$

Here, $s$ denotes the number of years before $t$, while $\delta_{1}$ and $\delta_{2}$ are endogenous parameters which indicate the rates of decay and diffusion. Thus, in eq. (6) the coefficient on the time-trend $\left(\alpha_{E T}\right)$

\footnotetext{
${ }^{5}$ The key obstacle is the dearth of data on patents by sector of use for the industries covered by our dataset, especially mining industries, utilities and communications, and services.

${ }^{6}$ The basic idea was introduced by Dowlatabadi and Oravetz (2006).

${ }^{7}$ The factor of 100 is introduced to improve the numerical stability of the estimation procedure.
} 
measures the influence of exogenous technological advance, while that on energy-saving knowledge ( $\left.\alpha_{E \text {, Knowledge }}\right)$ captures the cumulative impact of disembodied price-induced innovation.

A few caveats should be noted. First, this specification could hardly be more optimistic, as the definition of $\pi_{E}$ assumes that any increase in energy prices will induce energy-saving technical change. Thus, ITC will occur even if the positive price shock comes along after a significant decline in energy prices below their long-run average level—a situation in which there might well be little or no stimulus to innovate, as the techniques of production which are appropriate for higher energy-price regimes clearly already exist, and may be re-activated via substitution. ${ }^{8}$ However, the adverse impact of this potential misspecification is mitigated by the fact that strength of the inducement effect - and the influence of the resulting energy-saving knowledge on energy demand-depends on $\delta_{1}$ and $\delta_{2}$, whose values are conditioned on the data, controlling for the influence of energy-materials substitution.

A second issue is that the model gives the inducement effect of energy prices perhaps more prominence than is deserved, as it is likely that the prices of all inputs will simultaneously influence the creation of different kinds of productivity-enhancing knowledge. The stock of knowledge induced by shocks to the relative price of materials is not resolved. ${ }^{9}$ Had it been included, the total effect of all types of disembodied knowledge might well differ from that captured solely by eq. (10), suggesting the possibility of omitted variable bias. But to the extent that omitted knowledge stocks increase steadily in magnitude, their influence will be captured by the secular time trend, with the result that $\alpha_{E T}$ will reflect the additional impact of (latent) induced innovation which conserves non-energy inputs.

\footnotetext{
${ }^{8}$ See, e.g., the discussion in Sue Wing (2006: 5-7).

${ }^{9}$ Its inclusion was not possible due to limitations of computational cost, and especially degrees of freedom.
} 
Figure 2 illustrates the sensitivity of the stock of knowledge to the parameters by showing how eq. (10) depends on the values of $\pi_{E}, \delta_{1}$ and $\delta_{2}$. Panel A illustrates the impulse responses to a unit price shock as a function of the decay and diffusion parameters. Panel B shows the results of applying these response functions to the aggregate energy price series in Figure 1, whose positive shocks are indicated by the shaded areas. Larger (smaller) values of $\delta_{1}$ are associated with faster (slower) rates of decay due to obsolescence, and greater (lesser) persistence of the new knowledge whose creation was induced by the shock, while larger (smaller) values of $\delta_{2}$ are associated with faster (slower) rates of diffusion, and shorter (longer) lags between the onset of the shock and its maximum impact on knowledge creation. Consequently, larger values of the decay parameter are associated with smaller overall quantities of knowledge, while larger values of the diffusion parameter make the time-paths of the knowledge stocks more volatile. An additional feature of panel $\mathrm{B}$ is that prior to the mid-1970s the aggregate stock of energy-saving knowledge was negligible, reflecting the fact that energy prices varied only slightly over this period. We shall see that this ends up having an important bearing on the estimates of the timing of ITC's impact.

\subsection{The sources of change in energy intensity in the short and the long run}

The econometric model provides a unifying framework with which to elaborate the sources of change in energy intensity at the industry level. ${ }^{10}$ This is apparent from the discrete log-derivative of eq. (6):

$$
\frac{\Delta e_{i}}{e_{i}} \approx \sum_{v} \varepsilon_{E v i} \frac{\Delta p_{v i}}{p_{v i}}+\varepsilon_{E T i}+\mu_{E T i} \frac{\Delta \pi_{E i}}{\pi_{E i}}+\sum_{k} \eta_{E k i} \frac{\Delta x_{k i}}{x_{k i}}
$$

\footnotetext{
${ }^{10}$ For a similar approach employing a translog cost function see Welsch and Ochsen (2005).
} 
The left-hand side is the rate of change in sectoral energy intensity, while the right hand side partition this rate into components associated with changes in variable input prices, technology, and stocks of quasi-fixed inputs.

The parameter $\varepsilon_{E v i}$ is the short-run elasticity of energy intensity with respect to the price of the $v^{\text {th }}$ variable input,

$$
\varepsilon_{E v i}=\left(\partial e_{i} / \partial p_{v i}\right)\left(p_{v i} / e_{i}\right)=\alpha_{E v i} p_{v i} / e_{i}
$$

which measures the average substitution response to changes in variable input prices.

The parameters $\varepsilon_{E T i}$ and $\mu_{E T i}$ are the short-run elasticities of energy intensity with respect to time and contemporaneous energy price shocks, respectively:

$$
\begin{aligned}
& \varepsilon_{E T i}=\left(\partial e_{i} / \partial t\right)\left(1 / e_{i}\right)=\alpha_{E T i} / e_{i}, \\
& \mu_{E T i}=\left(\partial e_{i} / \partial x_{E, \text { Knowledge }, i}\right)\left(\partial x_{E, \text { Knowledge }, i} / \partial \pi_{E i}\right)\left(\pi_{E i} / e_{i}\right)=\alpha_{E, \text { Knowledge }, i}\left(1-\exp \left(-\delta_{2 i}\right)\right) \pi_{E i} / e_{i} .
\end{aligned}
$$

These expressions have a natural interpretation as the average rates of exogenous and induced disembodied technical progress.

The last set of parameters, $\eta_{E k i}$, are the long-run net elasticities of energy intensity with respect to the $k$ quasi-fixed inputs. Following Berndt, Morrison and Watkins (1981), I use a chain-rule argument to compute these estimates at the point where the capital stocks adjust to their long-run optimal levels: ${ }^{11}$

$$
\eta_{k E i}=\left(\frac{\partial e_{i}}{\partial x_{k i}}+\sum_{k} \frac{\partial e_{i}}{\partial x_{k i}^{*}} \frac{\partial x_{k i}^{*}}{\partial x_{k i}}\right) / \frac{e_{i}}{x_{k i}}=\alpha_{k E i} x_{k i} / e_{i},
$$

The results capture the net effects of adjustments in heterogeneous capital.

Subsumed within the final term on the right-hand side of eq. (11) are the long-run influences of the evolution of quasi-fixed input stocks on the price responsiveness and efficiency

\footnotetext{
${ }^{11}$ The corresponding short-run elasticities, $\varepsilon_{E k i}$, are zero by definition.
} 
of production. As previously mentioned, the direct effect of capital accumulation on energy intensity will be positive in so far as assets require energy to generate economic services.

Embodied innovations can directly counterbalance this effect by improving the energy efficiency of successive generations of assets. But they may also have the more subtle effect of making the production process more flexible, increasing the elasticity of substitution and the responsiveness of inputs demands to changes in relative prices. The first effect is identified from the interaction of capital and time, while the second is identified from the interaction of capital and variable input prices.

The proxies for these influences are the long-run analogues of (12) and (13) when quasifixed inputs have adjusted to their equilibrium levels, and they are computed in a manner similar to eq. (15). The additional effect of capital on input substitutability is captured by the long-run variable input price elasticities, $\eta_{E v i}$ :

$$
\eta_{E v i}=\left(\frac{\partial e_{i}}{\partial p_{v i}}+\sum_{k} \frac{\partial e_{i}}{\partial x_{k i}^{*}} \frac{\partial x_{k i}^{*}}{\partial p_{v i}}\right) / \frac{e_{i}}{p_{v i}}=\varepsilon_{E v i}+\sum_{k} \xi_{k v i}
$$

while its impact on efficiency is captured by the long-run average rate of technical progress, $\eta_{E T i}:^{12}$

$$
\eta_{E T i}=\frac{1}{e_{i}}\left(\frac{\partial e_{i}}{\partial t}+\frac{\partial e_{i}}{\partial x_{E, \text { Knowledge }, i}} \frac{\partial x_{E, \text { Knowledge }, i}}{\partial \pi_{E i}} \pi_{E i}+\sum_{k} \frac{\partial e_{i}}{\partial x_{k i}^{*}} \frac{\partial x_{k i}^{*}}{\partial t}\right)=\varepsilon_{E T i}+\mu_{E T i}+\sum_{k} \xi_{k T i}
$$

The difference between the short- and long-run elasticities is the additional effect of embodiment. Eq. (9) gives us the ability to identify how much of each type of influence is associated with a given type of capital:

\footnotetext{
${ }^{12}$ We do not identify the long-run rate of induced technical progress. To do so, we would have had to estimate $k$ additional interaction terms between $D_{E i}^{+}$and each type of capital, incurring an unacceptable loss of degrees of freedom.
} 


$$
\xi_{k v i}=-\frac{\alpha_{k E i} \alpha_{k v i} p_{v i}}{\alpha_{k k i} e_{i}} \quad \text { and } \quad \xi_{k T i}=-\frac{\alpha_{k E i} \alpha_{k T i}}{\alpha_{k k i} e_{i}}
$$

\subsection{The aggregate implications of industry-level intensity change}

I now turn to the second novel feature of the analysis, which is a method for assessing the implications of the aforementioned sectoral results at the aggregate level. My approach is to decompose aggregate intensity change into industry-level intensity change and structural change. I do this by modeling the ratio of aggregate energy use, $E^{A g g}$, to GDP, $Y^{A g g}$, as the weighted sum of the contemporaneous energy intensities of the $i$ industries in the economy:

$$
e_{t}^{A g g}=\frac{E_{t}^{A g g}}{Y_{t}^{A g g}}=\sum_{i=1}^{N} \phi_{i, t} e_{i, t},
$$

where each weight $\left(\phi_{i}\right)$ is the ratio of industry $i$ 's share of GDP to its share of total energy use. ${ }^{13}$ It is easily shown that the logarithmic derivative of this expression is: ${ }^{14}$

$$
\frac{\Delta e^{A g g}}{e^{A g g}}=\underbrace{\frac{1}{N} \sum_{i=1}^{N} \frac{\Delta \phi_{i}}{\phi_{i}}}_{\Phi}+\underbrace{\frac{1}{N} \sum_{i=1}^{N} \frac{\Delta e_{i}}{e_{i}}}_{\Psi} .
$$

The left-hand side of this expression has the natural interpretation as the average rate of change in aggregate energy intensity. Eq. (20) decomposes this quantity into two influences: the sum of changes in industries' contributions to aggregate energy intensity—the "structural change effect", $\Phi$, and the average of changes in energy intensity within industries—-the "efficiency change effect", $\Psi$.

The fundamental insight is that $\Psi$ is just the average across industries of eq. (11). Thus, in each time period, the impacts on aggregate energy intensity of substitution associated with

\footnotetext{
${ }^{13}$ Our decomposition is inspired by Hogan and Jorgenson (1991) eq. (8). Although more sophisticated formulae are possible (see, e.g., Ang and Zhang 2000), we employ eq. (19) because of its tractability and ease of interpretation.

14 The derivation is discussed in the supplementary material to the paper.
} 
changes in the prices of variable inputs, technological progress, or changes in the level and composition of capital, may be found by computing the industry average of the relevant term on the left-hand side of eq. (11).

\section{Data and Estimation}

To maximize the industry coverage of the econometric analysis, the KLEM dataset developed by Jorgenson and associates was used as the primary data source. This dataset records the real prices and quantities of output and inputs of capital, labor, energy and intermediate materials in 35 industries over the 43 -year period $1958-2000 .{ }^{15}$ These data define the prices and quantities of output and variable inputs.

Jorgenson's sectoral energy price series were adjusted to bring the corresponding energy quantity series into line with the trends in energy use by industry in official statistics. The first step was to construct new quantity indices of sectoral energy input from a variety of sources and re-base them to 1996 (the Jorgenson dataset's benchmark year). I retain Jorgenson's value of sectoral energy input, and divide this series by the new quantity indices to generate new series of energy prices by industry. The precise adjustments are described in detail in the supplementary materials.

Information on the different classes of quasi-fixed inputs is drawn from a secondary dataset, which is the real cost net capital stocks series by detailed asset and detailed industry from the BEA. ${ }^{16}$ The industry-by-asset series are truncated to match the time period of the Jorgenson dataset and apportioned among industry categories to match Jorgenson's sectoral disaggregation (approximately 2-digit SIC). The different assets were also aggregated into five

\footnotetext{
${ }^{15}$ I thank Jon Samuels for these data.

${ }^{16}$ BEA (2003) describes their construction.
} 
broad classes that define the set of quasi-fixed input categories $k$ : information and communication technology (IT), electrical equipment, machinery, vehicles, and buildings and structures.

Descriptive statistics for the final dataset are shown in Table 1. I append random error terms to eqs. (6)-(8) and estimate these expressions as a separate simultaneous equations time series regression with 45 free parameters for each industry. The resulting system was estimated using GMM, with the normalized variable input prices, the quasi-fixed input intensities, a time trend and the knowledge stocks as instruments. Andrews' (1991) technique was used to compute the standard errors, which are robust to autocorrelation of up to third order.

To construct the stocks of energy-saving knowledge it is necessary to compute the technological decay and diffusion coefficients, $\delta_{1}$ and $\delta_{2}$, in each sector. The values of these endogenous parameters were estimated along with the rest of the model using the method outlined in Popp (2001). Specifically, I defined auxiliary parameters $v, \lambda \in(0,1)$ such that $\delta_{1}=\frac{v}{1-v}$ and $\delta_{2}=\frac{\lambda}{1-\lambda}$, which enabled me to perform a grid search over $v$ and $\lambda$ to find the combination of their values which minimized the GMM criterion.

\section{Econometric Results}

The estimation results are too numerous to discuss in detail. The values, standard errors and levels of significance of the estimated coefficients of the energy intensity equation (6) for all 35 sectors are tabulated in the supplementary materials. The fit between the estimated equations and the data is generally good, however, the Durbin-Watson statistics suggest that first-order serial correlation remains an issue in just under half of the industries. 
Below I report summary measures of the elasticities of energy demand with respect to the covariates. The elasticities computed in section 2.2 are point parameters whose values vary with the temporal evolution of the dependent and independent variables. I therefore report their average values over the period of the sample, which is indicated by a bar over the relevant parameter. These quantities are computed by evaluating the variables in (13)-(18) at the means of the 43 years of data for each industry.

\subsection{Short- and long-run variable input price elasticities}

The estimates of the average variable input price elasticities are shown in Table 2 . The average short-run own-price elasticities, $\bar{\varepsilon}_{E E}$, are uniformly inelastic, significant in the majority of industries, and mostly of the expected sign. ${ }^{17}$

The average short-run cross-price elasticities for energy and materials, $\bar{\varepsilon}_{E M}$, are significant in just over half of the industries, and the majority of these suggest energy-using impacts. The energy-saving influence of materials prices is concentrated in mining, transportation and utilities, while the energy-using impacts are concentrated in manufacturing. The two elastic responses are both negative, occurring in the non-metal mining and communications sectors.

With regard to long-run impacts, 14 of the average own-price elasticities, $\bar{\eta}_{E E}$, are significant, with three being positive and two being elastic. ${ }^{18}$ We do not report the long-run energy-material cross-price elasticities, $\bar{\eta}_{E M}$, only three of which are significant, and are mostly

\footnotetext{
${ }^{17}$ The own-price energy elasticities are positive and significant only in the oil and gas mining, metal mining, gas utilities and wholesale and retail trade sectors.

${ }^{18}$ Elastic responses are exhibited by petroleum refining, which is large and positive, and electrical machinery, which is negative.
} 
energy using. ${ }^{19}$ This suggests that the influence of embodied innovations on the fungibility of variable inputs has had a negligible overall impact on energy intensity.

\subsection{Quasi-fixed input elasticities}

Table 2 also presents long-run average net elasticities of sectoral energy intensity with respect to the different types of capital, $\bar{\eta}_{k E}$. IT capital, electrical equipment and machinery all have decidedly mixed impacts, with equal numbers of industries exhibiting significant elasticities of either sign. IT capital exhibits uniformly inelastic responses, which are significant in 13 sectors. Elasticities with respect to electrical equipment and machinery are significant in 23 and 21 sectors (respectively), and are evenly divided in sign. Elastic responses to the first type of capital occur in four industries and are all positive, while responses to the second are positive and elastic in five industries and negative and elastic in four. Vehicles and structures are both predominantly energy-using. The response of energy demand to changes in vehicle stocks is elastic in only three industries. ${ }^{20}$ By contrast, elastic responses to structures occur in a large number of sectors, with positive estimates in seven industries and negative estimates in five. Given the mix of positive and negative influences associated with the different types of capital, the previous finding that embodiment has little net impact on substitution is unsurprising.

\subsection{Stocks of Energy-Saving Knowledge}

I first present estimates of the stocks of energy-saving knowledge before going on to describe their effects on energy demand. The estimates of $\delta_{1}$ and $\delta_{2}$ in Table 3 indicate that the rates of decay and particularly diffusion of energy-saving knowledge tend to be slow, with a few

\footnotetext{
${ }^{19}$ Non-metal mining and furniture manufacturing exhibit elastic responses, with the former being negative and the latter positive.

${ }^{20}$ Of these construction and lumber and wood are positive, while financial services is negative.
} 
signal exceptions. ${ }^{21}$ The average lag before which energy prices shocks induce the maximum amount of knowledge, $T_{\text {Peak, } i}=\log \left(1-\delta_{2 i} / \delta_{1 i}\right) / \delta_{2 i}$, ${ }^{22}$ ranges from virtually instantaneous to several decades, with a median value of 2.6 years. Figure 3 shows the impulse response of knowledge to technological inducement at the median values of $\delta_{1}$ and $\delta_{2}$. Its time profile is similar to Popp's (2001) Figure 4, but although there is a similar median lag between the onset of the price shock and the maximum impact on innovation (and energy savings), the present stocks of knowledge decay twice as fast, and the maximum impact on knowledge accumulation is only 50 percent larger than the instantaneous effect—roughly a quarter of that found by Popp. The implication of these dynamics is that the effects of ITC dissipate after 20 years, which has an important bearing on the estimates of the effect of technical progress on energy intensity.

\subsection{Elasticities of technical change}

Table 4 summarizes the influences of technical change on industries' conditional energy demand. By way of comparison, panels A and B report prior estimates by Jorgenson and Fraumeni (1981) and Jorgenson (1984) for the period prior to 1980. Panels C and D present estimates for the parameters $\alpha_{E T}$ and $\alpha_{E \text {, Knowledge }}$ for the period 1958-2000, and panels E-G tabulate the corresponding average short-run elasticities of energy intensity with respect to exogenous and induced technical change, $\bar{\varepsilon}_{E T}$ and $\bar{\mu}_{E T}$.

Jorgenson and Fraumeni’s (1979) estimates are significant in all but six industries and suggest that the effect of technical change is overwhelmingly energy using. Jorgenson's (1984) results exhibit more variability, but still show a dominant pattern of energy-using technical progress across industries. His estimates for both electric and non-electric energy inputs are

\footnotetext{
${ }^{21}$ e.g., coal mining, textiles, rubber and plastics, gas utilities, financial services and government enterprises.

${ }^{22}$ Note that $T_{\text {Peak, } i}=\arg \max _{t}\left\{\exp \left(-\delta_{1 i} t\right)\left(1-\exp \left(-\delta_{2 i} t\right)\right)\right\}$.
} 
positive and significant in 14 sectors, and negative and significant in only three. For the remaining sectors, the secular trends in the conditional demands for electricity and non-electric energy are either not significant, or have opposing signs, suggesting an ambiguous overall effect. $^{23}$ The magnitude of these estimates is generally small, and their cross-industry distribution is negatively skewed. For both electric and non-electric energy, the average of the significant estimates is negative while the median is positive, reflecting Jorgenson's finding that prior to 1980 the influence of technological change on energy demand was small and positive in many industries, but large and negative in a small number of industries. ${ }^{24}$

The estimates of the effects of the exogenous and induced components of these trends over the longer sample in panels $\mathrm{C}$ and $\mathrm{D}$ are in contrast to the earlier results. The impact of exogenous technical change is significant in 20 sectors, half of which exhibit energy saving responses. The proxy for induced technical change is significant in nine sectors, four of which show a negative influence. The coefficients on autonomous technical change are similar in magnitude to those in the Jorgenson studies, while those on ITC are very large, exceeding the former by one to two orders of magnitude.

These results indicate that technical progress had a negative overall influence on industries' energy intensity. Moreover, they suggest that industries' energy-saving response to induced innovation was very strong, exceeding even that found Popp (cf. his Table 5), which is in apparent contrast to Linn's (2006) findings. However, considerable care is necessary in interpreting these results. The impacts of ITC depends on the sectoral input intensities of energysaving knowledge $\left(x_{\text {Knowledge }}\right)$, whose magnitudes tend to be quite small, especially when

\footnotetext{
${ }^{23}$ The latter situation prevails in nine industries.

${ }^{24}$ In the case of electric energy input, the industries with the five largest estimated coefficients all exhibit an energysaving bias, while in the case of non-electric energy inputs, the largest estimated coefficient is negative and an order of magnitude bigger than the second-largest.
} 
compared to the stocks of physical capital. Consequently, its ultimate impact is far more modest that the coefficients in panel D seem to imply. An additional issue is that the ITC coefficient is not precisely estimated in many industries, which is symptomatic of collinearity between $p_{E}$ and $X_{\text {Knowledge, }}{ }^{25}$ and reflects the difficulties that arise from using an input based proxy for innovation instead of an observable measure of innovatory output such as patent counts. Replacing $\pi_{E}$ with the latter might well improve the estimates in this regard. However, the extent to which this might change the results, and in what direction, are questions that I leave to future research.

The average elasticities in panels $\mathrm{E}$ and $\mathrm{F}$ are mostly inelastic, and their signs correspond to those of the relevant parameter estimates. Across industries, the overall effects on energy intensity of both exogenous and induced technical change are negative and substantial. Consequently, the average net elasticities of energy demand with respect to technical progress, shown in panel $\mathrm{G}$, closely parallel the estimates in panel $\mathrm{F}^{26}$ To conserve space I do not report the average long-run elasticities of technical change, $\bar{\eta}_{E T}$, which are very similar to the estimates in panel $\mathrm{G}$. The latter are dominated by the elastic impacts with respect to induced innovation in four industries: electrical machinery, which is energy using, and construction, chemicals and services, which are all strongly energy saving.

\subsection{Embodied technical change}

The data on quasi-fixed inputs are noisy, consequently the impact of the evolution of physical quasi-fixed inputs on input substitutability and efficiency are estimated with precision in only in a few industries. To conserve space I tabulate the detailed estimates in the supplementary

\footnotetext{
${ }^{25}$ Across industries, the correlation between these variables ranged from -0.67 to 0.83 with a mean of 0.33 .

${ }^{26}$ There are 13 industries in which exogenous technical change is significant but the combined effect of exogenous and induced technical change is insignificant. By contrast, the latter measure is significant is every industry where induced technical change is significant
} 
materials, and only give a brief summary of the key results. The average effects of asset accumulation on sectors' own-price elasticity of demand for energy, $\bar{\xi}_{k E}$, are small and mostly positive. The impact on industries' energy-material cross-price elasticities is similarly minor, with significant values of $\bar{\xi}_{k M}$ in five sectors, all of which are negative (with the exception of structures in the food products sector). The estimated impact of embodiment on energy

efficiency, $\bar{\xi}_{k T}$, are slightly energy saving for information technology and electrical equipment, mixed for machinery, and predominantly energy using for vehicles and structures.

The dearth of precise estimates makes it difficult to draw robust conclusions, but the pattern of significant effects suggests that embodied technical change may have a more pronounced impact on efficiency improvement than on the flexibility of production. There are also indications that while capacity expansion may limit the potential to conserve energy in response to energy price increases, it may enhance the substitutability of materials for energy. Finally, the sign of the particular influence changes depending on the specific quasi-fixed input under consideration, with energy intensity being amplified by the efficiency impacts of vehicles and structures, but attenuated by the effects of IT capital on both efficiency and materials-energy substitution.

\section{Explaining the Trend in Aggregate Energy Intensity}

\subsection{Results of the decomposition analysis}

Chained indices for the effects $\Phi$ and $\Psi$ were calculated using the output quantity and energy input quantity series for the 35 industries in the dataset. I also calculated the fractional change in the energy-GDP ratio using aggregate energy consumption from DOE/EIA (2005) and real GDP from the NIPAs. Figure 4 presents chained indices of the structural change effect, the 
intensity change effect, and aggregate energy intensity. The joint impact of these effects (i.e., the sum of the chained indices of $\Phi$ and $\Psi$ ) closely tracks $\Delta E^{A g g} / E^{A g g}$, indicating that the disparate data sources at the aggregate and sectoral levels tell a consistent story about the character of changes in U.S. energy intensity.

The trajectories of $\Phi$ and $\Psi$ explain the decline in intensity in the U.S. from 1958-2000. They indicate that until 1973, most of the reduction was due to changes in the sectoral composition of the economy. The latter changes are responsible for a 20 percent reduction in aggregate energy intensity from its 1958 level. This early decline was mostly offset by increases in energy intensity within industries. After the first OPEC oil shock the effects of structural change slowed down while that of efficiency change reversed direction. As a result, throughout the 1980s and 1990s the impact of changes in the sectoral composition of output was relatively less important, contributing to an additional 15 percent reduction in aggregate intensity, while industries' unit energy demands declined rapidly until the end of the sample period, falling by 36 percent to end up 15 percentage points below its 1958 level.

The individual industry dynamics underlying these aggregate trends are noisy, but the contributions of a few sectors stand out. Metal mining, crude oil and gas, leather and government enterprises experience large increases in energy intensity relative to the 1958 base year, but these industries are in the minority. After the mid-1970s, the intensity of energy use falls in two-thirds of the industries in the sample. Most of these declines were modest, with cumulative intensity reductions of less than 50 percent relative to sectors' 1958 levels, but those in the chemicals, electrical and non-electrical machinery, and communications industries were very large. Thus, rather than being driven by large efficiency increases in a few key sectors, the decline in $\Psi$ appears to be the result of slow and systematic improvements over a broad cross-section of 
industries in the economy. We now employ the econometric results of the previous section to elucidate the origins of this phenomenon.

\subsection{The sources of efficiency change}

By combining eqs. (11) and (20), we are able to estimate the impacts of the different sources of intra-industry efficiency change at the aggregate level. We construct chained indices of the left-hand side of eq. (11), whose evolution is shown in Figure 5. Over the long run, the substitution effects associated with variable input prices tended to increase aggregate energy intensity, while technological progress, as well as the net effects of the accumulation and changes in the composition of quasi-fixed inputs, tended to have the opposite effect. The energyusing influence of substitution is slight prior to 1973 and pronounced during the period of low energy prices after 1993, increasing the intensity of industries' energy use by four percent over the 1959 level. In the interregnum, variable input price movements were associated with large energy-saving effects, particularly over the years 1974-1986, where they reduced intra-sectoral energy intensity by more than 12 percent relative to 1959 .

The influence of technical change is very slightly energy using prior to 1980 and energy saving thereafter, ultimately giving rise to a nine-percent reduction in energy intensity below the 1959 level. Quasi-fixed inputs have an energy-using influence over two-thirds of the sample.

Prior to 1980 they are associated with increases in energy intensity of 17 percent above 1959 levels, but subsequently exhibit a dramatic decline which reduced energy intensity by 36 percent below its starting value.

The chained index of the sum of these various factors tracks the intra-industry efficiency index reasonably well, but it tends to overstate the reduction in energy intensity over much of the 
sample. This behavior can be traced to the residual errors in eq. (6), as well as a lack of precision in the estimated coefficients, whose values were set to zero if they did not achieve at least the ten percent level of significance.

Figures 6-8 shed light on the underpinnings of these trends. Figure 6 elucidates the different substitution responses associated with the relative prices of energy and materials. While the dynamics of the substitution effect in Figure 5 are largely driven by energy prices, the aggregate impact of material prices is uniformly energy-saving, which reduces intensity in the long run by more than seven percent below its 1958 level. This effect both moderates the substitution toward energy when the latter's price is low, and amplifies the energy-saving influence of substitution throughout the period of the OPEC price shocks.

Figure 7 illustrates the effects of the components of technical change on the efficiency of industries' energy use. Exogenous technical progress is the primary driver of the long-run energy-saving impact of innovation seen in Figure 5, which reduces intensity by more than five percent from its 1959 level. Induced innovation is energy-saving as well, but its ultimate effect is two-thirds as large. Interestingly, the early 1980s are a watershed period for technical change in two respects: The impact of induced innovation, which before that time was negligible, begins to have a significant impact, and the influence of autonomous technical progress switches direction from slightly energy using to strongly energy saving. ${ }^{27}$

\footnotetext{
${ }^{27}$ It bears emphasizing that the apparent breaks in the aggregate trends in the influence of technical progress on intensity occurs in the absence of breakpoints in the underlying estimated industry-level trends. The clear implication of eq. (6) is that the signs of $\alpha_{E, T}$ and $\alpha_{E \text {, Knowledge }}$ are constant for each industry over the entire sample period, and Table 4 indicates that the corresponding elasticities $\varepsilon_{E, T}$ and $\mu_{E, T}$ are positive in some industries and negative in others. The shift in the sign of their influence at the macro level is a consequence of changes in the contributions of the various sectors to the efficiency component of aggregate energy intensity-in particular the larger weight enjoyed by those sectors which exhibit an energy-saving bias of technical change. This fact is most transparent in the case of autonomous technical change, where, by (11), (13) and (20) the component of $\Psi$ attributable to this factor is computed as $\frac{1}{N} \sum_{i=1}^{N} \frac{\alpha_{E T i}}{e_{i, t}}$. Over time, industries in which $\alpha_{E, T}<0$ experience relatively
} 
These estimates suggest that Popp's results on the energy-saving influence of induced innovation are in fact consistent with Jorgenson's early finding of energy-using bias of technical change. The keys to the resolution of this puzzle are (i) the lags in the response of energy-saving knowledge to the energy price shocks of the 1970s, and (ii) the differential responses of individual industries' energy demands to their own knowledge stocks, in conjunction with (iii) the evolving relative contributions of different sectors to both GDP and aggregate energy use.

It is worth noting the relatively small influence that ITC has on the energy-GDP ratio, an impact which will likely be further attenuated by a less optimistic treatment of the inducement effect of energy prices. Even so, the policy implications are not immediately clear-especially with respect to the problem of climate change. On one hand, the finding of a limited role for induced innovation would appear to support the conclusions drawn by Nordhaus (2002) from simulations. But mitigation measures are also expected to precipitate a steady increase in the prices of fossil fuels as constraints on GHG emissions bind more tightly on the economy, which under the current structural assumptions would provide a continual stimulus to the accumulation of energy-saving knowledge. As a result, it is also plausible that energy savings due to ITC will become increasingly important over the long time horizon over which emission limits are projected to bind.

Figure 8 captures the implications of Newell et al's (1999) results, demonstrating that shifts in the composition of quasi-fixed inputs were as important as of changes in asset characteristics for the long-run evolution of energy intensity. Prior to 1980, virtually all types of

larger declines in $e$, causing the contribution of their influence to increase, which eventually reverses the direction of technology's overall effect on aggregate intensity. The emergence of a similar pattern in the case of ITC suggests that both autonomous and induced innovations were acting in the same direction at the same time, but this result raises suspicion as to whether ITC's influence is properly identified. 
capital had energy-using effects, with IT capital and vehicles exerting negligible additional influences relative to 1959 , and the remaining assets increasing energy intensity by one to six percent above the initial level. ${ }^{28}$ In the wake of the first energy price shock the energy-using influence of electrical equipment declined from its high of four percent above the 1959 level, with its effect remaining at its initial level throughout the 1980s before falling sharply in the 1990s. After the second price shock the influence of vehicle capital stocks declined as well, plummeting from three percent above the initial level of intensity to 14 percent below. ${ }^{29}$ The influence of structures mirrors that of equipment, peaking in the 1970s before returning to initial levels and undergoing a rapid decline in the early 1990s, falling seven percent in less than a decade. Machinery's influence is consistently energy-using throughout the sample, in the 1980s declining slightly from its peak of six percentage points and remaining essentially constant thereafter.

An additional feature of these results in that the impact of IT capital became slightly energy-using in the late 1980s before exploding during the internet boom of the 1990s, raising aggregate energy intensity by six percent in as many years. This increase was large enough to completely offset the substantial energy savings associated with equipment, vehicles and structures. Thus, notwithstanding information technology's widespread association with embodied energy-saving technical progress, the uptick in energy use warranted by the rapid

\footnotetext{
${ }^{28}$ Vehicles were associated with a slight reduction in aggregate intensity from 1959 levels over the period of the late 1960 s and early 1970s.

${ }^{29}$ This effect is most likely the result of the influence of corporate average fuel economy (CAFE) mandates on vehicle energy efficiency. The fuel economy of the vehicle fleet increased by one third between 1977 and 1988, but has remained essentially constant since then (NRC 2002). The latter is period is precisely when the energy-saving impact of vehicles in Figure 8 stagnates.
} 
accumulation of IT capital in the late 1990s appears to have substantially outweighed the latter's contribution to output over this period. ${ }^{30}$

I close with a summary of the main points. Table 5 puts the influence of the foregoing factors in context by comparing their contributions to the change in aggregate energy intensity. The decline in intensity over the last four decades of the $20^{\text {th }}$ century is predominantly due to structural change, but after 1980 the importance of this factor wanes in comparison to improvements in the efficiency of energy use with industries. The latter is primarily due to changes in the composition of quasi-fixed inputs, which in turn is largely attributable changes in energy demand associated with vehicle stocks. In terms of the energy-saving influences, disembodied technological progress in a distant second. The driving force behind its effect is autonomous technical change, while induced technical change has the smallest impact of the energy-saving factors considered, beneath the influences of materials prices and the stocks of electrical equipment and structures. The most striking feature of the results is the reversal of direction in the drivers of intra-industry efficiency change between the first and second halves of the sample. Quasi-fixed inputs and disembodied technical progress both have an energy-using influence prior to 1980 and an energy-saving influence thereafter, while substitution exhibits the symmetric opposite response.

\section{Conclusions}

The story of the substantial decline in the energy intensity of the U.S. economy over the latter half of the past century is not a simple one. We have shown that it is mainly the result of changes in industrial composition and disembodied technological progress-especially of the

\footnotetext{
${ }^{30}$ This result is an interesting counterpoint to Jorgenson and Stiroh (1999): IT capital raised the U.S. economy's speed limit, but accelerating economic growth required a greater-than-proportional increase in energy use!
} 
autonomous variety. Substitution due to shifts in the relative price of energy has had a transitory effect, attenuating intensity in during energy price shocks but amplifying it when energy prices returned to their long-run levels. Innovation induced by energy price increases has had a consistently energy saving effect, which is the smallest of all of the factors considered.

Finally, although the analysis in the paper strives to be comprehensive, these results are by no means the last word on the origins of the historical decline in energy intensity. In particular, there is room for improvement on two fronts: development of improved estimates of the influence of ITC, and better characterization of the impact of embodied technical progress on energy demand. In the first instance, a key step is to identify the inducement effects of the prices of the various inputs on an output-based proxy for innovation (e.g., patents) while simultaneously estimating the propensity to innovate along with the influence of knowledge stocks on input demands. Progress on the second front hinges on the ability to estimate how the influences of contemporaneous innovations become capitalized into quasi-fixed inputs. This is likely to involve re-specification of the econometric model to include of interactions between the stocks of knowledge and tangible quasi-fixed inputs. Both of these issues are priorities for future research. 


\section{References}

1. Acemoglu, D. (2002). Directed Technical Change, Review of Economic Studies 69(4): 781809.

2. Ang, B.W. and F.Q. Zhang (2000). A survey of index decomposition analysis in energy and environmental studies, Energy 25: 1149-1176.

3. Andrews, D.W.K. (1991). Heteroskedasticity and Autocorrelation Consistent Covariance Matrix Estimation, Econometrica 59(3): 817-858.

4. Berndt, E.R., C. Morrison and G.C. Watkins (1981). Dynamic models of energy demand: an assessment and comparison, in: B.C. Field and E.R. Berndt (eds.), Modeling and Measuring Natural Resource Substitution, Cambridge MA: MIT Press, 259-289.

5. Berndt, E.R. (1990). Energy Use, Technical Progress and Productivity Growth: A Survey of Economic Issues," Journal of Productivity Analysis 2: 67-83.

6. Berndt, E.R., and D.O. Wood (1987). Energy Price Shocks and Productivity Growth: A Survey, in R.L. Gordon, H.D. Jacoby and M.B. Zimmerman (eds.), Energy: Markets and Regulation, Cambridge MA: MIT Press, 305-342.

7. BEA (2003). Fixed Assets and Consumer Durable Goods in the United States, 1925-99. Washington DC: U.S. Government Printing Office.

8. DOE/EIA (2005). Annual Energy Review 2005, Washington DC.

9. Dowlatabadi, H. and M.A. Oravetz (2006). U.S. long-term energy intensity: Backcast and projection, Energy Policy 34: 3245-3256.

10. Edmonds, J. and J.M. Reilly (1985). Global Energy: Assessing the Future, New York: Oxford University Press. 
11. Hirst, E., R. Marlay and D. Geene (1983). Recent Changes in United States Energy Consumption: What Happened and Why, Annual Review of Energy 8: 193-245

12. Hogan, W.W. and D.W. Jorgenson (1991). Productivity Trends and the Cost of Reducing Carbon Dioxide Emissions, Energy Journal 12(1): 67-85.

13. Hicks, J. (1932). A Theory of Wages, London: Macmillan.

14. Jorgenson, D.W. and B.M. Fraumeni (1981). Relative Prices and Technical Change, in E. Berndt and B. Field (eds.), Modeling and Measuring Natural Resource Substitution, Cambridge: MIT Press, 17-47.

15. Jorgenson, D.W. (1984). The Role of Energy in Productivity Growth, in J.W. Kendrick (ed.), International Comparisons of Productivity and Causes of the Slowdown, Cambridge MA: Ballinger, 279-323.

16. Jorgenson, D.W. and K.J. Stiroh (1999). Information Technology and Growth, American Economic Review 89: 109-115.

17. Levin, R., A. Klevorick, R.R. Nelson and S.G. Winter (1987) . Appropriating the Returns from Industrial R\&D, Brookings Papers on Economic Activity 3 (Special Issue on Microeconomics): 783-831.

18. Linn, J. (2006). Energy Prices and the Adoption of Energy-Saving Technology, MIT CEEPR Working Paper no. WP 06-012, Cambridge MA.

19. Manne, A.S. and R.G. Richels (1992). Buying Greenhouse Insurance, Cambridge: MIT Press.

20. National Research Council (2002). Effectiveness and Impact of Corporate Average Fuel Economy (CAFE) Standards, Washington DC: National Academies Press. 
21. Newell, R.G., R.N. Stavins and A.B. Jaffe (1999). The Induced Innovation Hypothesis and Energy-Saving Technological Change, Quarterly Journal of Economics 114: 941-975.

22. Nordhaus, W.D. (2002). Modeling Induced Innovation in Climate-Change Policy, in A. Gruebler, N. Nakicenovic, and W.D. Nordhaus (eds.), Technological Change and the Environment, Washington, D.C.: Resources for the Future Press, 182-209.

23. Popp, D. (2001). The Effect of New Technology on Energy Consumption, Resource and Energy Economics 23: 215-239.

24. Popp, D. (2002). Induced Innovation and Energy Prices, American Economic Review 92: 160-180.

25. Rose, A.Z. and C.Y. Chen (1991). Sources of Change in the Structure of Energy Use in the U.S. Economy: A Structural Decomposition Analysis, Resource and Energy Economics 13(1):1-21.

26. Schipper, L., R.B. Howarth and H. Geller (1990). United States Energy Use from 1973 to 1987: The Impacts of Improved Efficiency, Annual Review of Energy and the Environment 15: 455-504.

27. Sue Wing, I. (2006). Representing induced technological change in models for climate policy analysis, Energy Economics, in press.

28. Watkins, G.C. and E.R. Berndt (1992). Dynamic models of input demands: a comparison under different formulations of adjustment costs, in J.R. Moroney (ed.), Advances in the Economics of Energy and Resources, Greenwich CT: JAI Press, 159-188.

29. Welsch, H. and C. Ochsen (2005). The Determinants of Aggregate Energy Use in West Germany, Energy Economics 27: 93-111. 
30. Williams, R.H. (1990). Low Cost Strategies for Coping with $\mathrm{CO}_{2}$ Emission Limits, Energy Journal 11(4): 35-59. 


\section{Table 1. Descriptive Statistics of the Dataset}

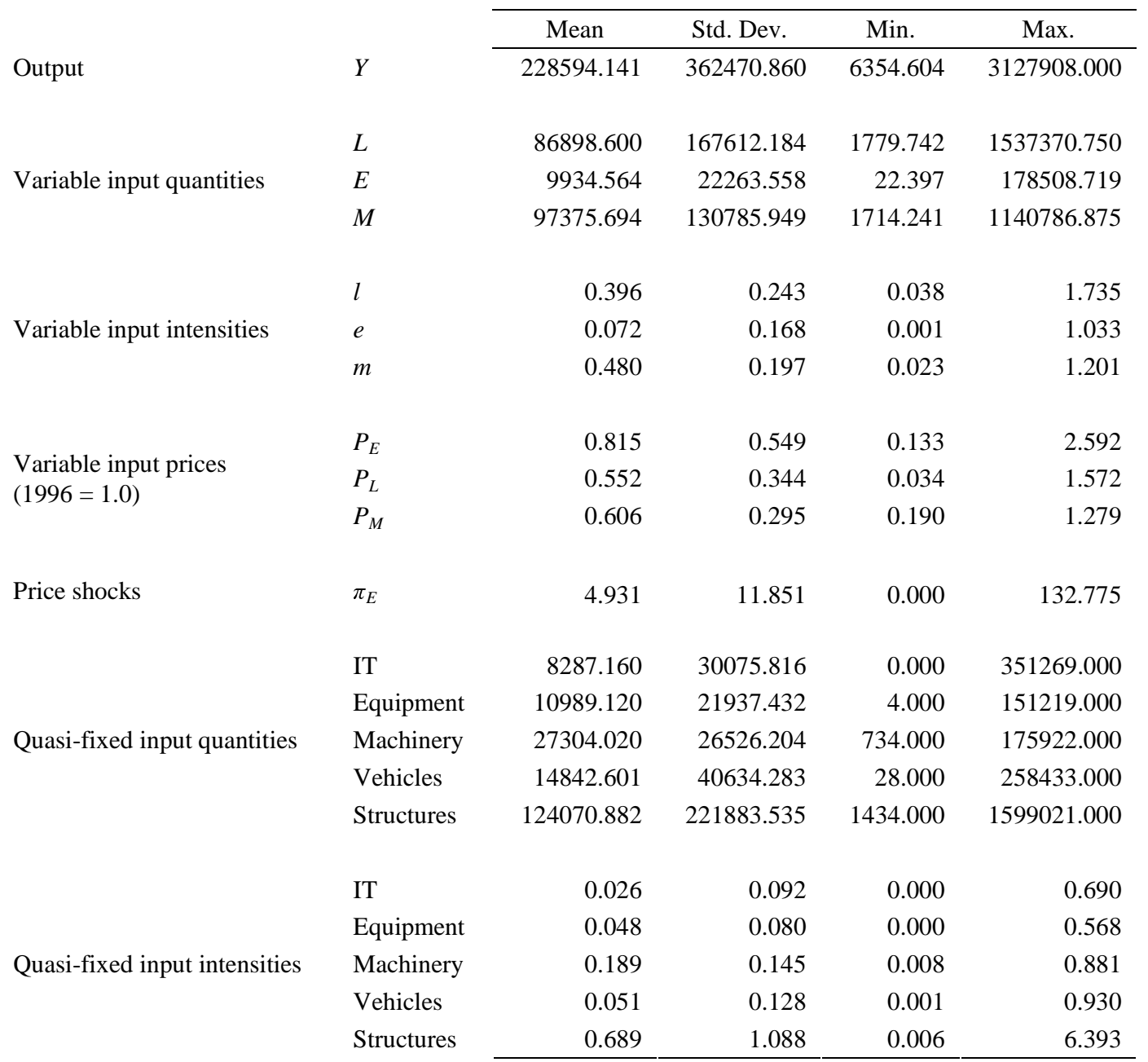

No. of industries: 35 . No. of years: 42 . No. of observations: 1470 . Variable input prices are divisia index numbers, variable input quantities are real quantity indexes in millions of 1996 dollars, computed by dividing nominal expenditures on inputs by the corresponding input price series. Quasi-fixed input quantities are real values in millions of 1996 dollars. 
Table 2. Short-Run Variable Input Price and Long-Run Quasi-Fixed Input Elasticities of Energy Demand

\begin{tabular}{|c|c|c|c|c|c|c|c|c|c|c|c|c|c|c|c|c|}
\hline \multirow[b]{4}{*}{ Agriculture } & \multicolumn{4}{|c|}{ A. Short-run Elasticities } & \multicolumn{12}{|c|}{ B. Long-run Elasticities } \\
\hline & \multirow{2}{*}{\multicolumn{2}{|c|}{$\begin{array}{c}\text { Own-price energy } \\
\bar{\varepsilon}_{E E}\end{array}$}} & \multirow{2}{*}{\multicolumn{2}{|c|}{$\begin{array}{c}\text { Energy-materials } \\
\bar{\varepsilon}_{E M}\end{array}$}} & \multirow{2}{*}{\multicolumn{2}{|c|}{$\begin{array}{l}\text { Own-price energy } \\
\bar{\eta}_{E E}\end{array}$}} & \multirow{2}{*}{\multicolumn{2}{|c|}{$\begin{array}{l}\text { Information tech. } \\
\bar{\eta}_{\pi, E}\end{array}$}} & \multirow{2}{*}{\multicolumn{2}{|c|}{$\begin{array}{l}\text { Equipment } \\
\bar{\eta}_{\text {Equiment }, E}\end{array}$}} & \multirow{2}{*}{\multicolumn{2}{|c|}{$\begin{array}{c}\text { Machinery } \\
\bar{\eta}_{\text {Mactiner }, E}\end{array}$}} & \multirow{2}{*}{\multicolumn{2}{|c|}{$\begin{array}{l}\text { Vehicles } \\
\bar{\eta}_{\text {Vadices }, E}\end{array}$}} & \multirow{2}{*}{\multicolumn{2}{|c|}{$\begin{array}{l}\text { Structures } \\
\bar{\eta}_{\text {Smencurs }, E}\end{array}$}} \\
\hline & & & & & & & & & & & & & & & & \\
\hline & -0.27 & $(0.06) * * *$ & 0.39 & $(0.13)^{* * * *}$ & -0.27 & $(0.06)^{* * *}$ & -0.02 & $(0.08)$ & 0.09 & $(0.18)$ & 0.11 & $(0.39)$ & 0.38 & $(0.39)$ & 0.30 & $(0.37)$ \\
\hline Metal mining & 0.06 & $(0.25)$ & -0.08 & $(0.25)$ & 0.44 & $(0.62)$ & -0.27 & $(0.06)^{* * *}$ & 0.66 & $(0.31)^{* *}$ & 0.63 & $(0.19)^{* * * *}$ & 0.03 & $(0.16)$ & $\underline{-1.09}$ & $(0.63)^{*}$ \\
\hline Coal mining & -0.34 & $(0.12)^{* * *}$ & 0.19 & $(0.10)^{*}$ & -0.97 & (4.93) & -0.05 & $(0.08)$ & 0.24 & $(0.33)$ & -0.27 & $(0.21)$ & 0.29 & $(0.16)^{*}$ & $\underline{1.07}$ & $(0.15) * * *$ \\
\hline Crude oil \& gas & 0.22 & $(0.08)^{* * * *}$ & -0.18 & $(0.11)^{*}$ & 14.77 & $(252.79)$ & -0.34 & $(0.44)$ & $\underline{1.47}$ & $(0.84)^{*}$ & 0.99 & $(0.64)$ & 0.56 & $(0.37)$ & $-\overline{-3.05}$ & $(0.91) * * *$ \\
\hline Non-metal mining & 0.55 & $(0.16)^{* * *}$ & -1.22 & $(0.18)^{* * *}$ & 0.58 & $(0.18) * * *$ & -0.04 & $(0.01)^{* * *}$ & $-\overline{-0.30}$ & $(0.10)^{* * *}$ & -0.23 & $(0.14)^{*}$ & 0.14 & $(0.07)^{*}$ & 0.37 & $(0.15) * *$ \\
\hline Construction & -0.42 & $(0.07)^{* * * *}$ & -0.20 & $(0.31)$ & -0.49 & $(0.08)^{* * *}$ & -0.15 & $(0.09)^{*}$ & 0.75 & $(0.29)^{* *}$ & $\underline{-1.19}$ & $(0.52)^{* *}$ & $\underline{1.53}$ & $(0.49)^{* * * *}$ & -0.06 & $(0.26)$ \\
\hline Food \& allied & -0.31 & $(0.07)^{* * *}$ & 0.29 & $(0.14)^{* *}$ & -0.54 & $(41.40)$ & 0.03 & $(0.04)$ & 0.30 & $(0.42)$ & $\overline{-0.84}$ & $(0.58)$ & $\overline{0.11}$ & $(0.09)$ & 2.16 & $(0.41) * * *$ \\
\hline Tobacco & -0.26 & $(0.10)^{* * *}$ & 0.17 & $(0.09)^{*}$ & -0.26 & $(0.10)^{* *}$ & 0.38 & $(0.07) * * *$ & -0.57 & $(0.08)^{* * *}$ & -0.55 & $(0.21)^{* * * *}$ & 0.18 & $(0.12)$ & $\overline{0.95}$ & $(0.23) * * *$ \\
\hline Textile mill prod. & -0.26 & $(0.05)^{* * *}$ & -0.40 & $(0.10)^{* * *}$ & -0.18 & $(0.16)$ & -0.02 & $(0.05)$ & 0.00 & $(0.05)$ & $\underline{1.35}$ & $(0.43)^{* * * *}$ & 0.00 & $(0.14)$ & -0.70 & $(0.43)$ \\
\hline Apparel & -0.32 & $(0.05)^{* * * *}$ & -0.50 & $(0.30)^{*}$ & -0.33 & $(0.07) * * *$ & -0.07 & $(0.06)$ & 0.47 & $(0.21)^{* *}$ & $\overline{0.29}$ & $(0.24)$ & -0.14 & $(0.09)$ & -0.33 & $(0.39)$ \\
\hline Lumber \& wood & -0.28 & $(0.10)^{* * *}$ & 0.26 & $(0.25)$ & 0.22 & $(0.68)$ & 0.24 & $(0.05)^{* * *}$ & 0.37 & $(0.15)^{* *}$ & -2.93 & $(0.53)^{* * * *}$ & $\underline{1.09}$ & $(0.18)^{* * *}$ & $\underline{1.15}$ & $(0.48)^{* *}$ \\
\hline Furn. \& fixtures & -0.28 & $(0.05)^{* * *}$ & 0.86 & $(0.23)^{* * *}$ & -0.26 & $(0.07) * * *$ & -0.03 & $(0.07)$ & -0.19 & $(0.06)^{* * *}$ & $\overline{0.46}$ & $(0.40)$ & $\overline{0.22}$ & $(0.13)^{*}$ & $-\overline{0.14}$ & $(0.41)$ \\
\hline Paper \& allied & -0.20 & $(0.06)^{* * *}$ & -0.06 & $(0.15)$ & -0.21 & $(0.14)$ & -0.03 & $(0.03)$ & -0.07 & $(0.22)$ & -0.26 & $(0.35)$ & 0.05 & $(0.07)$ & 0.90 & $(0.35)^{* *}$ \\
\hline Printing \& pub. & -0.27 & $(0.04)^{* * *}$ & 0.41 & $(0.22)^{*}$ & -0.25 & $(0.04)^{* * * *}$ & 0.00 & $(0.02)$ & -0.16 & $(0.05)^{* * *}$ & 0.51 & $(0.26)^{* *}$ & 0.00 & $(0.09)$ & -0.05 & $(0.24)$ \\
\hline Chemicals & -0.16 & $(0.11)$ & 0.21 & $(0.19)$ & 0.60 & $(1.41)$ & 0.03 & $(0.07)$ & -0.58 & $(0.39)$ & $\underline{3.24}$ & $(1.21)^{* * *}$ & 0.71 & $(0.59)$ & $\underline{-2.75}$ & $(1.32) * *$ \\
\hline Petroleum \& coal & -0.01 & $(0.01)^{* * * *}$ & 0.02 & $(0.01)^{* *}$ & $\underline{4.48}$ & $(2.56)^{*}$ & 0.06 & $(0.06)$ & 0.11 & $(0.07)$ & $\overline{-0.30}$ & $(0.08)^{* * * *}$ & 0.04 & $(0.02)^{* *}$ & 0.69 & $(0.11) * * *$ \\
\hline Rubber \& plastics & -0.70 & $(0.11)^{* * *}$ & 0.19 & $(0.15)$ & $-\overline{0.75}$ & $(0.28)^{* * *}$ & 0.10 & $(0.03)^{* * *}$ & -0.24 & $(0.03)^{* * *}$ & -0.83 & $(0.26)^{* * *}$ & -0.28 & $(0.08)^{* * *}$ & $\underline{1.59}$ & $(0.30) * * *$ \\
\hline Leather & -0.52 & $(0.07)^{* * * *}$ & 0.46 & $(0.12)^{* * *}$ & -0.95 & $(1.54)$ & 0.36 & $(0.07) * * *$ & -0.55 & $(0.07)^{* * *}$ & -0.03 & $(0.29)$ & -0.37 & $(0.16)^{* *}$ & $\underline{1.04}$ & $(0.29) * * *$ \\
\hline Stone clay \& glass & -0.31 & $(0.10)^{* * *}$ & 0.81 & $(0.20)^{* * *}$ & 2.20 & $(6.61)$ & -0.22 & $(0.05)^{* * *}$ & 0.10 & $(0.05)^{* *}$ & $\underline{2.18}$ & $(0.37)^{* * * *}$ & 0.50 & $(0.09)^{* * *}$ & -2.39 & $(0.53) * * *$ \\
\hline Primary metal & -0.19 & $(0.04)^{* * *}$ & 0.20 & $(0.07)^{* * * *}$ & 0.11 & $(5.25)$ & -0.16 & $(0.03)^{* * *}$ & -0.17 & $(0.11)$ & $\overline{0.98}$ & $(0.22)^{* * * *}$ & 0.13 & $(0.06)^{* *}$ & $\overline{-0.73}$ & $(0.27) * * *$ \\
\hline Fabricated metal & -0.34 & $(0.04)^{* * *}$ & -0.14 & $(0.15)$ & -0.29 & $(0.27)$ & 0.06 & $(0.06)$ & -0.05 & $(0.29)$ & -0.19 & $(0.31)$ & -0.27 & $(0.09)^{* * *}$ & 0.82 & $(0.50)^{*}$ \\
\hline Non-elec. mach. & -0.28 & $(0.08)^{* * *}$ & 0.38 & $(0.18)^{* *}$ & 0.29 & $(0.42)$ & 0.17 & $(0.09)^{*}$ & -0.28 & $(0.13)^{* *}$ & $\underline{-1.79}$ & $(0.18)^{* * * *}$ & -0.07 & $(0.06)$ & $\underline{2.24}$ & $(0.17) * * *$ \\
\hline Electrical mach. & -1.00 & $(0.18)^{* * *}$ & 0.32 & $(0.35)$ & -1.19 & $(0.51)^{* *}$ & -0.98 & $(0.40)^{* *}$ & 1.66 & $(0.47)^{* * *}$ & -0.26 & $(0.51)$ & 0.19 & $(0.39)$ & $-\overline{0.24}$ & $(0.64)$ \\
\hline Motor vehicles & -0.42 & $(0.10)^{* * *}$ & 0.52 & $(0.21)^{* *}$ & $\overline{0.06}$ & $(3.07)$ & -0.11 & $(0.11)$ & $-\overline{0.29}$ & $(0.15)^{*}$ & $\underline{1.11}$ & $(0.37)^{* * * *}$ & 0.09 & $(0.10)$ & -0.75 & $(0.38)^{*}$ \\
\hline Trn. equip. \& ord. & -0.38 & $(0.08)^{* * *}$ & 0.41 & $(0.18)^{* *}$ & -0.43 & $(40.12)$ & -0.04 & $(0.06)$ & 0.21 & $(0.51)$ & 0.28 & $(0.25)$ & -0.15 & $(0.15)$ & 0.04 & $(0.45)$ \\
\hline Instruments & -0.25 & $(0.06)^{* * *}$ & -0.14 & $(0.20)$ & -0.23 & $(0.07)^{* * * *}$ & 0.07 & $(0.04)$ & -0.05 & $(0.06)$ & 0.94 & $(0.31)^{* * * *}$ & 0.01 & $(0.06)$ & -0.41 & $(0.43)$ \\
\hline Misc. mfg. & -0.27 & $(0.05)^{* * *}$ & -0.09 & $(0.19)$ & -0.24 & $(0.11)^{* *}$ & 0.02 & $(0.09)$ & -0.26 & $(0.10)^{* * *}$ & -0.30 & $(0.61)$ & -0.15 & $(0.13)$ & 0.78 & $(0.73)$ \\
\hline Transportation & -0.06 & $(0.01)^{* * * *}$ & -0.17 & $(0.06)^{* * *}$ & -0.06 & $(0.03)^{* *}$ & 0.09 & $(0.02)^{* * * *}$ & -0.06 & $(0.02)^{* * *}$ & -0.21 & $(0.04)^{* * * *}$ & 0.41 & $(0.04)^{* * *}$ & 0.06 & $(0.05)$ \\
\hline Communications & 0.24 & $(0.17)$ & -1.01 & $(0.57)^{*}$ & 0.19 & $(9.78)$ & -0.25 & $(0.45)$ & 2.44 & $(0.40)^{* * *}$ & -0.32 & $(0.13)^{* *}$ & -0.38 & $(0.24)$ & 0.61 & $(0.64)$ \\
\hline Electric utilities & -0.13 & $(0.01)^{* * *}$ & 0.24 & $(0.02)^{* * *}$ & -0.03 & $(0.03)$ & -0.07 & $(0.01) * * *$ & $\overline{0.12}$ & $(0.07)^{*}$ & 0.27 & $(0.05)^{* * * *}$ & -0.04 & $(0.03)$ & -0.19 & $(0.03) * * *$ \\
\hline Gas utilities & 0.02 & $(0.01)^{* * * *}$ & -0.04 & $(0.01)^{* * * *}$ & -186.50 & $(2,047.65)$ & -0.01 & $(0.05)$ & 0.57 & $(0.09) * * *$ & -1.04 & $(0.13)^{* * * *}$ & -0.13 & $(0.12)$ & 1.21 & $(0.24)^{* * * *}$ \\
\hline Trade & 0.38 & $(0.20)^{*}$ & -0.60 & $(0.50)$ & 0.39 & $(0.20)^{*}$ & 0.03 & $(0.06)$ & -0.41 & $(0.14)^{* * *}$ & -0.90 & $(0.63)$ & 0.13 & $(0.14)$ & $\overline{0.42}$ & $(0.79)$ \\
\hline Financial Serv. & -0.23 & $(0.26)$ & -0.04 & $(0.44)$ & -0.20 & $(0.39)$ & 0.13 & $(0.10)$ & 4.09 & $(1.20)^{* * *}$ & 0.62 & $(0.36)^{*}$ & $\underline{-3.37}$ & $(0.80)^{* * *}$ & -1.69 & $(0.97)^{*}$ \\
\hline Services & -0.02 & $(0.09)$ & -0.21 & $(0.29)$ & -0.01 & $(0.09)$ & 0.04 & $(0.04)$ & $\overline{0.53}$ & $(0.48)$ & 0.28 & $(0.20)$ & 0.17 & $(0.22)$ & -0.37 & $(0.32)$ \\
\hline Gov't. enterprises & -0.24 & $(0.16)$ & 0.01 & $(0.27)$ & -0.71 & $(0.89)$ & 0.08 & $(0.07)$ & -0.99 & $(0.23)^{* * *}$ & $\underline{1.06}$ & $(0.20)^{* * *}$ & 0.70 & $(0.29)^{* *}$ & 0.06 & $(0.73)$ \\
\hline $\operatorname{Mean}^{\dagger}$ & -0.24 & & 0.09 & & 0.08 & & -0.04 & & 0.37 & & 0.17 & & 0.05 & & 0.08 & \\
\hline $\operatorname{Median}^{\dagger}$ & -0.27 & & 0.20 & & -0.25 & & -0.04 & & -0.06 & & 0.27 & & 0.18 & & 0.76 & \\
\hline
\end{tabular}

Standard errors in parentheses are robust to third-order autocorrelation. Significance: $10 \% *, 5 \% * *, 1 \% * * *$. Elastic positive and significant energy demand responses are underlined and in bold. Elastic negative and significant energy demand responses are underlined and in italics. ${ }^{\dagger}$ Significant estimates only. 
Table 3. Induced Technological Change: Rates of Decay and Diffusion

\begin{tabular}{lrrr}
\hline & Decay ${ }^{\mathrm{a}}$ & Diffusion $^{\mathrm{b}}$ & $\begin{array}{c}T_{\text {Peak }}{ }^{\mathrm{c}} \\
\text { (years) }\end{array}$ \\
\hline Agriculture & 0.01 & 0.01 & 68.62 \\
Metal mining & 0.69 & 0.05 & 1.39 \\
Coal mining & 24.00 & 32.33 & 0.03 \\
Crude oil \& gas & 0.32 & 0.02 & 3.07 \\
Non-metal mining & 1.00 & 0.01 & 0.99 \\
Construction & 0.01 & 0.01 & 68.62 \\
Food \& allied & 2.57 & 0.41 & 0.36 \\
Tobacco & 0.59 & 0.03 & 1.66 \\
Textile mill prod. & 49.00 & 9.00 & 0.02 \\
Apparel & 0.01 & 0.01 & 68.62 \\
Lumber \& wood & 0.01 & 0.01 & 68.62 \\
Furn. \& fixtures & 0.19 & 0.01 & 5.12 \\
Paper \& allied & 0.03 & 0.01 & 27.98 \\
Printing \& pub. & 0.18 & 0.01 & 5.51 \\
Chemicals & 0.01 & 0.01 & 68.62 \\
Petroleum \& coal & 0.45 & 0.02 & 2.18 \\
Rubber \& plastics & 15.67 & 3.17 & 0.06 \\
Leather & 1.13 & 0.10 & 0.85 \\
\hline
\end{tabular}

\begin{tabular}{lrrr}
\hline & Decay $^{\mathrm{a}}$ & Diffusion $^{\mathrm{b}}$ & \multicolumn{1}{c}{$\begin{array}{l}T_{\text {Peak }}{ }^{\mathrm{c}} \\
\text { (years) }\end{array}$} \\
\hline Stone clay \& glass & 0.33 & 0.10 & 2.63 \\
Primary metal & 0.01 & 0.01 & 68.62 \\
Fabricated metal & 0.01 & 0.01 & 68.62 \\
Non-elec. mach. & 0.01 & 0.01 & 68.62 \\
Electrical mach. & 0.43 & 0.01 & 2.31 \\
Motor vehicles & 0.05 & 0.03 & 14.95 \\
Trn. equip. \& ord. & 0.01 & 0.01 & 68.62 \\
Instruments & 0.52 & 0.10 & 1.78 \\
Misc. mfg. & 0.16 & 0.03 & 5.62 \\
Transportation & 1.00 & 0.02 & 0.99 \\
Communications & 2.03 & 0.02 & 0.49 \\
Electric utilities & 0.04 & 0.01 & 21.49 \\
Gas utilities & 32.33 & 2.23 & 0.03 \\
Trade & 0.37 & 0.02 & 2.63 \\
Financial services & 49.00 & 3.76 & 0.02 \\
Services & 0.02 & 0.02 & 33.96 \\
Gov't. enterprises & 49.00 & 32.33 & 0.02 \\
& & & \\
\hline
\end{tabular}

${ }^{\mathrm{a}}$ mean $=6.61$, median $=0.33 ;{ }^{\mathrm{b}}$ mean $=2.40$, median $=0.02 ;{ }^{\mathrm{c}}$ mean $=21.53$, median $=2.63$. 
Table 4. Short-Run Technical Change Elasticities of Energy Demand

Agriculture

Metal mining

Coal mining

Crude oil \& gas

Non-metal mining

Construction

Food \& allied

Tobacco

Textile mill prod.

Apparel

Lumber \& wood

Furn. \& fixtures

Paper \& allied

Printing \& pub.

Chemicals

Petroleum \& coal

Rubber \& plastics

Leather

Stone clay \& glass

Primary metal

Fabricated metal

Non-elec. mach.

Electrical mach

Motor vehicles

Trn. equip. \& ord.

Instruments

Misc. mfg.

Transportation

Communications

Electric utilities

Gas utilities

Trade

Financial Serv.

Services

Gov't. enterprises

Mean ${ }^{\dagger}$

Median $^{\dagger}$

Median

\begin{tabular}{|c|c|c|c|c|c|c|c|c|c|c|}
\hline \multicolumn{5}{|c|}{ Parameter estimates } & \multicolumn{6}{|c|}{ Elasticities } \\
\hline \multirow{2}{*}{$\begin{array}{l}\text { A. Jorgenson- } \\
\text { Fraumeni } \\
(1981) \\
1953-1974 \\
\end{array}$} & \multicolumn{2}{|c|}{$\begin{array}{c}\text { B. Jorgenson (1984) } \\
1958-1979\end{array}$} & \multirow{2}{*}{$\begin{array}{c}\text { C. Autonomous } \\
\text { innovation } \\
\alpha_{E T i}\end{array}$} & \multirow{2}{*}{$\begin{array}{l}\text { D. Induced } \\
\text { Innovation } \\
\alpha_{E \text {, Knowledgei }}\end{array}$} & \multirow{2}{*}{\multicolumn{2}{|c|}{$\begin{array}{l}\text { E. Autonomous } \\
\text { innovation } \\
\bar{\varepsilon}_{E T}\end{array}$}} & \multirow{2}{*}{\multicolumn{2}{|c|}{$\begin{array}{c}\text { F. Induced } \\
\text { innovation } \\
\bar{\mu}_{E T}\end{array}$}} & \multirow{2}{*}{\multicolumn{2}{|c|}{$\begin{array}{c}\text { G. Disembodied } \\
\text { technical change } \\
\bar{\varepsilon}_{E T}+\bar{\mu}_{E T}\end{array}$}} \\
\hline & Electricity & $\begin{array}{l}\text { Other } \\
\text { energy }\end{array}$ & & & & & & & & \\
\hline $1.77 \mathrm{E}-03$ & $-6.77 \mathrm{E}-05$ & $7.14 \mathrm{E}-04$ & $5.56 \mathrm{E}-05$ & -35.34 & 0.001 & $(0.006)$ & -0.676 & $(0.474)$ & -0.674 & $\begin{array}{l}(0.471) \\
\end{array}$ \\
\hline $2.43 \mathrm{E}-04$ & $6.75 \mathrm{E}-04$ & $-8.84 E-04$ & $2.76 \mathrm{E}-03$ & 1.82 & 0.028 & $(0.008) * * *$ & 0.085 & $(0.052)^{*}$ & 0.113 & $(0.052)^{* *}$ \\
\hline$-4.33 E-03$ & $-8.30 E-04$ & $-6.12 E-03$ & $-3.34 E-03$ & 0.04 & -0.021 & $(0.008) * * *$ & 0.011 & $(0.027)$ & -0.010 & $(0.029)$ \\
\hline 9.79E-04 & $-1.51 \mathrm{E}-04$ & 8.80E-04 & $-2.54 \mathrm{E}-03$ & -340.55 & -0.018 & $(0.015)$ & -2.182 & (1.741) & -2.199 & (1.739) \\
\hline 1.33E-04 & 8.34E-04 & $2.85 \mathrm{E}-05$ & 4.29E-05 & 0.26 & 0.003 & $(0.009)$ & 0.189 & $(0.432)$ & $\overline{0.191}$ & $(0.430)$ \\
\hline$-2.57 \mathrm{E}-05$ & $1.27 \mathrm{E}-04$ & $9.38 \mathrm{E}-05$ & $5.88 \mathrm{E}-05$ & -0.08 & 0.020 & $(0.005) * * *$ & -0.066 & $(0.043)$ & -0.046 & (0.043) \\
\hline $3.66 \mathrm{E}-04$ & $2.15 \mathrm{E}-04$ & $1.59 \mathrm{E}-04$ & $-3.23 \mathrm{E}-04$ & -0.02 & -0.010 & $(0.009)$ & -0.016 & $(0.101)$ & -0.026 & (0.099) \\
\hline 4.79E-04 & $1.05 \mathrm{E}-04$ & 2.02E-04 & $1.15 \mathrm{E}-05$ & -14.75 & 0.001 & (0.008) & -0.646 & $(0.253) * *$ & -0.645 & $(0.252) * *$ \\
\hline $1.97 \mathrm{E}-03$ & $2.80 \mathrm{E}-04$ & $4.83 \mathrm{E}-05$ & $-1.63 E-03$ & -15.20 & -0.079 & $(0.018) * * *$ & -0.479 & $(0.313)$ & -0.558 & $(0.310)^{*}$ \\
\hline $1.43 E-03$ & $-3.58 E-03$ & $-5.93 E-05$ & $4.91 \mathrm{E}-04$ & 0.44 & 0.033 & $(0.009) * * *$ & 0.011 & $(0.138)$ & 0.044 & $(0.138)$ \\
\hline $7.67 \mathrm{E}-04$ & $2.67 \mathrm{E}-04$ & $3.51 \mathrm{E}-04$ & $1.47 \mathrm{E}-04$ & -10.36 & 0.004 & $(0.005)$ & -0.106 & $(0.212)$ & -0.102 & $(0.210)$ \\
\hline $2.87 E-03$ & $-3.03 E-03$ & $3.47 \mathrm{E}-04$ & $-7.13 \mathrm{E}-05$ & 0.23 & -0.001 & $(0.006)$ & 0.010 & $(0.265)$ & 0.009 & $(0.265)$ \\
\hline$-7.21 \mathrm{E}-05$ & $1.86 \mathrm{E}-04$ & $-3.65 E-03$ & $-1.09 \mathrm{E}-06$ & -12.46 & 0.000 & $(0.005)$ & -0.218 & (0.159) & -0.218 & $(0.157)$ \\
\hline $1.04 \mathrm{E}-03$ & $2.97 \mathrm{E}-04$ & $4.85 \mathrm{E}-04$ & $-5.26 E-04$ & -18.05 & -0.023 & $(0.004) * * *$ & -0.246 & (0.397) & -0.268 & $(0.395)$ \\
\hline $2.89 \mathrm{E}-03$ & $-3.78 E-03$ & 4.01E-04 & $-7.93 E-04$ & 21.35 & -0.028 & $(0.007) * * *$ & 0.199 & $(0.344)$ & 0.171 & $(0.342)$ \\
\hline $9.01 \mathrm{E}-04$ & $8.17 E-05$ & 8.73E-05 & $-9.56 \mathrm{E}-05$ & 147.57 & -0.003 & $(0.017)$ & 1.505 & $(0.367) * * *$ & 1.502 & $(0.370) * * *$ \\
\hline $3.30 \mathrm{E}-04$ & $1.34 \mathrm{E}-04$ & $7.55 \mathrm{E}-05$ & 2.14E-04 & 2.21 & 0.022 & $(0.007) * * *$ & 0.302 & $(0.517)$ & 0.324 & $(0.518)$ \\
\hline $1.97 \mathrm{E}-04$ & $7.10 \mathrm{E}-05$ & 1.10E-04 & $-5.39 \mathrm{E}-05$ & -2.56 & -0.005 & $(0.009)$ & -0.109 & $(0.408)$ & -0.114 & $(0.406)$ \\
\hline $4.60 \mathrm{E}-04$ & $8.42 \mathrm{E}-05$ & $1.99 \mathrm{E}-04$ & $-1.70 E-04$ & -0.42 & -0.014 & $(0.008)^{*}$ & -0.188 & $(0.118)$ & -0.202 & $(0.118) *$ \\
\hline $1.99 \mathrm{E}-03$ & $-4.44 \mathrm{E}-05$ & $-4.30 E-01$ & $1.59 \mathrm{E}-04$ & 2.10 & 0.010 & $(0.006) *$ & 0.211 & $(0.200)$ & 0.221 & $(0.199)$ \\
\hline 8.45E-04 & $1.08 E-05$ & 7.48E-04 & $-3.93 E-04$ & 35.75 & -0.005 & $(0.002)^{* *}$ & 0.619 & $(0.277)^{* *}$ & 0.614 & $(0.277)^{* *}$ \\
\hline$-3.50 E-04$ & 1.34E-04 & $1.48 \mathrm{E}-05$ & $2.82 \mathrm{E}-04$ & -9.60 & 0.027 & $(0.016) *$ & -0.483 & $(0.754)$ & -0.456 & $(0.755)$ \\
\hline $9.99 \mathrm{E}-03$ & 2.16E-03 & $5.92 \mathrm{E}-03$ & $1.08 E-03$ & 22.41 & 0.008 & $(0.001) * * *$ & 0.057 & $(0.060)$ & 0.065 & $(0.060)$ \\
\hline $6.21 \mathrm{E}-03$ & 4.07E-04 & $7.24 \mathrm{E}-04$ & $-1.19 E-02$ & 0.03 & -0.029 & $(0.003) * * *$ & 0.004 & $(0.108)$ & -0.025 & $(0.108)$ \\
\hline $1.92 \mathrm{E}-04$ & $-7.08 E-04$ & $-8.33 E-04$ & $-5.63 \mathrm{E}-04$ & -131.67 & -0.019 & $(0.025)$ & -2.046 & (3.106) & -2.065 & (3.097) \\
\hline
\end{tabular}


Standard errors in parentheses are robust to third-order autocorrelation. Significance: $10 \% *, 5 \% * *, 1 \% * * *$. Positive and significant energy demand responses are shown in bold. Negative and significant energy demand responses are shown in italics. ${ }^{\dagger}$ Significant estimates only. 
Table 5. The Drivers of Long-Run Changes in Aggregate Energy Intensity ${ }^{*}$

\begin{tabular}{crrr}
\hline & \multicolumn{3}{c}{ Percentage change for period: } \\
& $1958-1979$ & $1980-2000$ & $1958-2000$ \\
\hline Inter-sectoral structural change & $\mathbf{- 1 8 . 9}$ & $\mathbf{- 1 3 . 7}$ & $\mathbf{- 3 2 . 6}$ \\
Intra-sectoral efficiency change & $\mathbf{7 . 6}$ & $\mathbf{- 2 5 . 2}$ & $\mathbf{- 1 7 . 6}$ \\
Substitution assoc. w/. variable inputs & -3.4 & 7.4 & 4.0 \\
Energy & 0.3 & 11.7 & 12.0 \\
Materials & -3.7 & -3.5 & -7.2 \\
Disembodied technical progress & 0.4 & -9.1 & -8.8 \\
Autonomous & 0.7 & -6.0 & -5.4 \\
Induced & -0.3 & -3.3 & -3.5 \\
Quasi-fixed inputs & 6.9 & -23.0 & -16.1 \\
Information technology & -0.3 & 5.6 & 5.3 \\
Electrical equipment & -1.2 & -3.9 & -5.1 \\
Machinery & 2.6 & 0.4 & 3.1 \\
Vehicles & 1.6 & -16.0 & -14.4 \\
Structures & 4.1 & -9.2 & -5.1 \\
\hline
\end{tabular}

* Totals may not add due to rounding. 
Figure 1. U.S. Energy Intensity and Energy Prices, 1958-1996

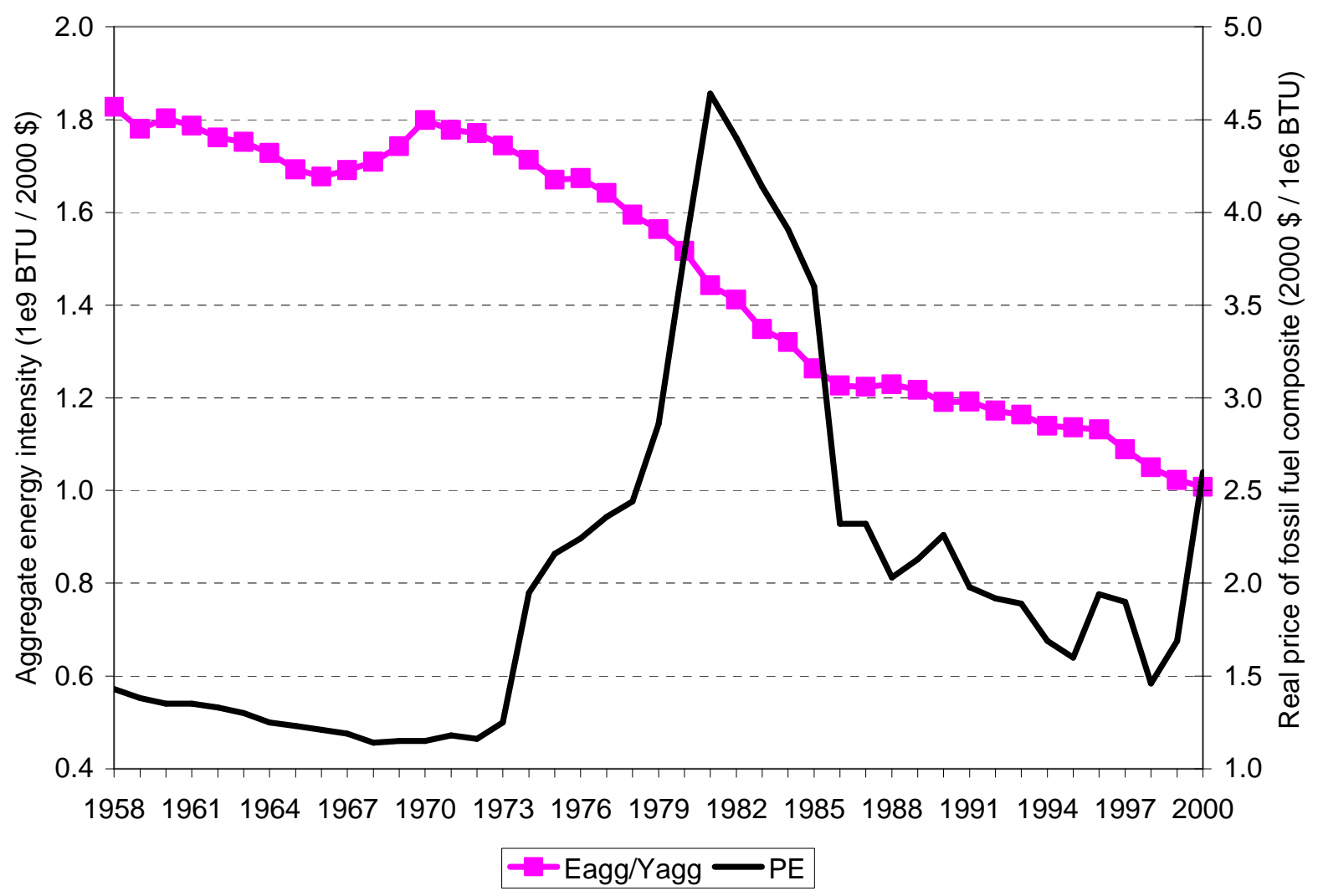

Source: BEA (2000); DOE/EIA (2005). 
Figure 2. Induced Innovation and Aggregate Energy Price Shocks

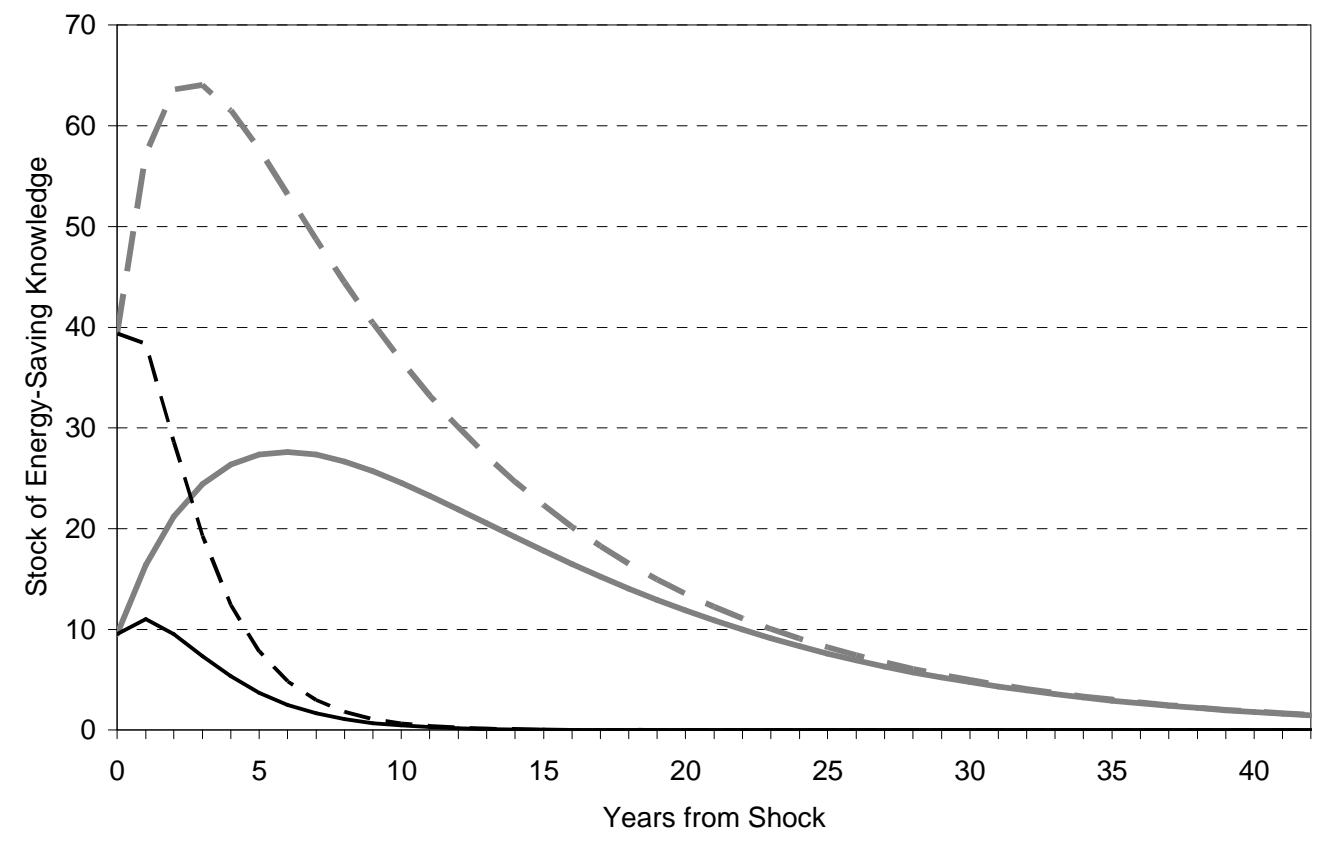

$\square \delta 1=0.1, \delta 2=0.1-\delta 1=0.1, \delta 2=0.5-\delta 1=0.5, \delta 2=0.1--\delta 1=0.5, \delta 2=0.5$

A. Impulse responses of knowledge to a shock $\pi_{E}=100$ for different values of $\delta_{1}$ and $\delta_{2}$

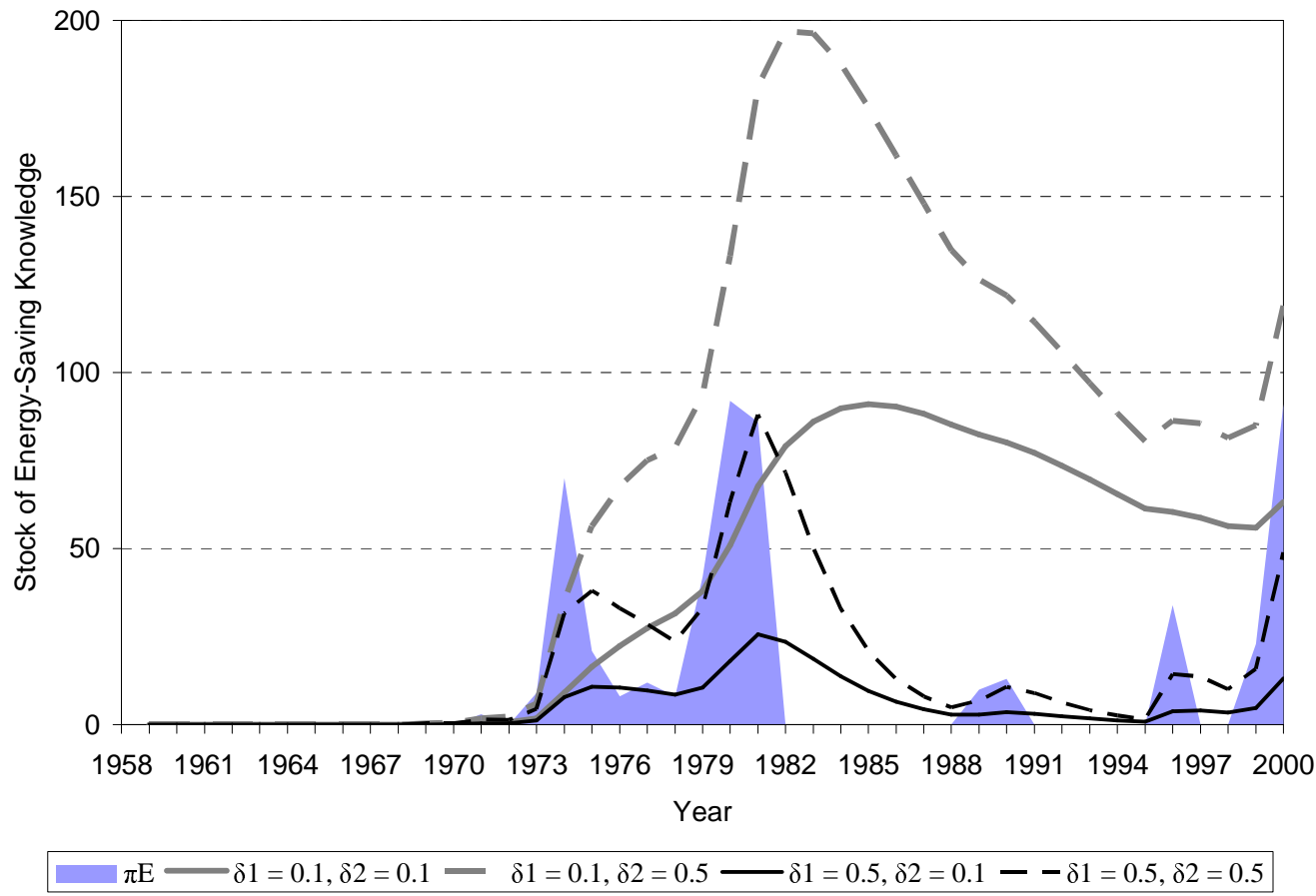

B. Knowledge stocks generated by $\pi_{E}$ in Figure 1 for different values of $\delta_{1}$ and $\delta_{2}$ 
Figure 3. Impact of Induced Innovation on Energy-Saving Knowledge at the Sample Median

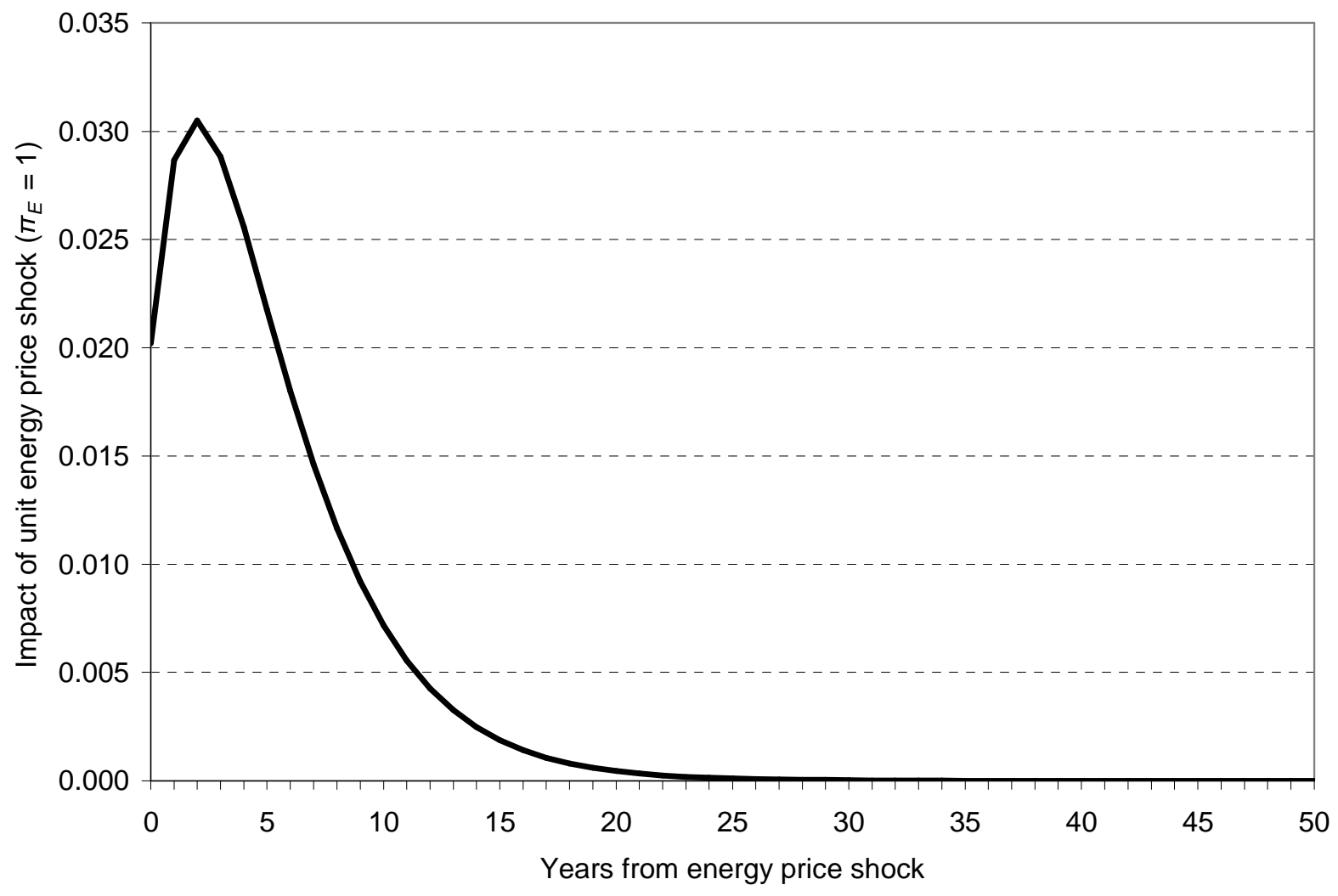


Figure 4. Indices of the Structural $(\Phi)$ and Efficiency $(\Psi)$ Components of the Change in Aggregate Energy Intensity $\left(E^{A g g} / Y^{A g g}\right), 1958-2000$

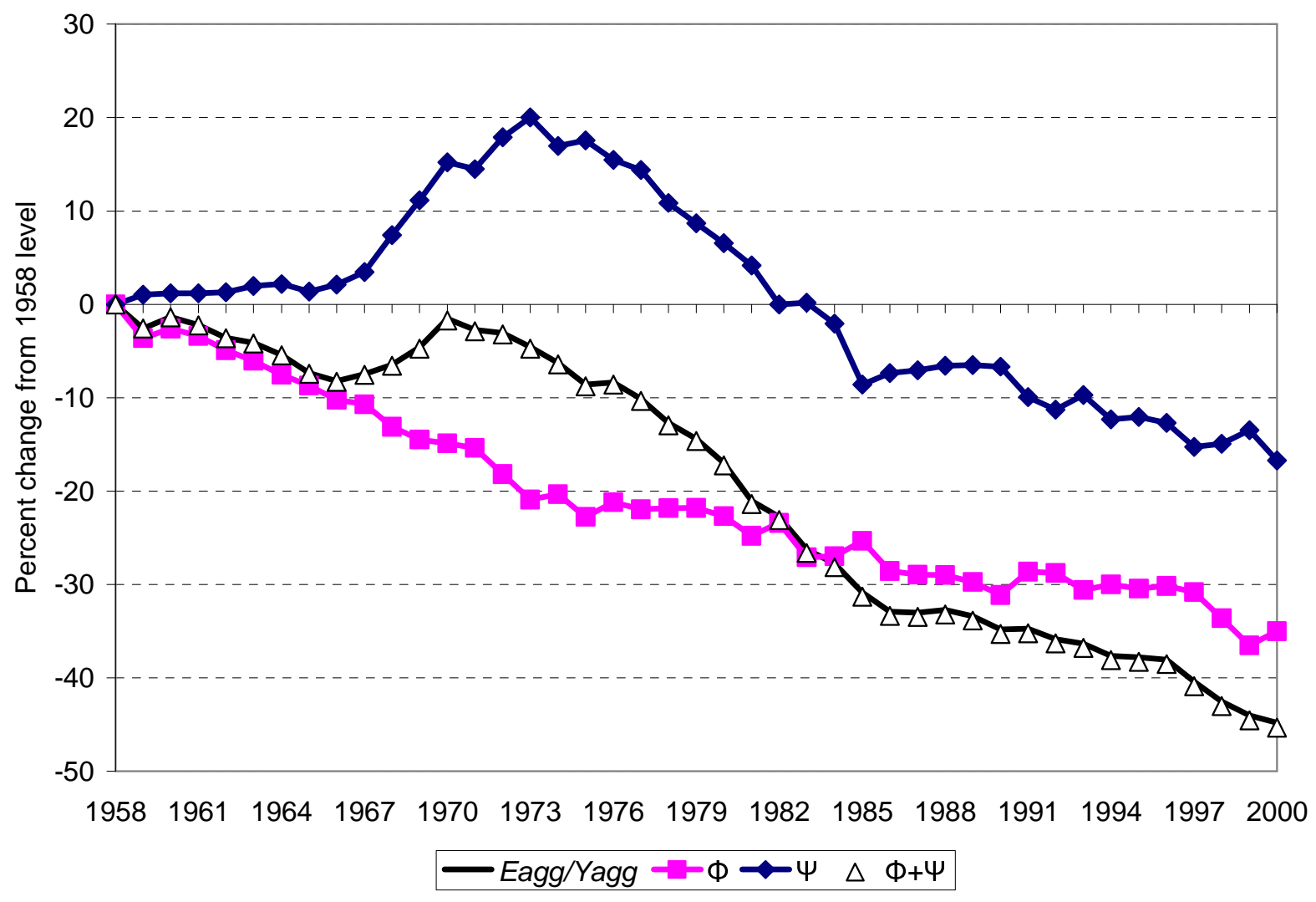


Figure 5. The Sources of Within-Industry Change in Energy Intensity, 1959-2000

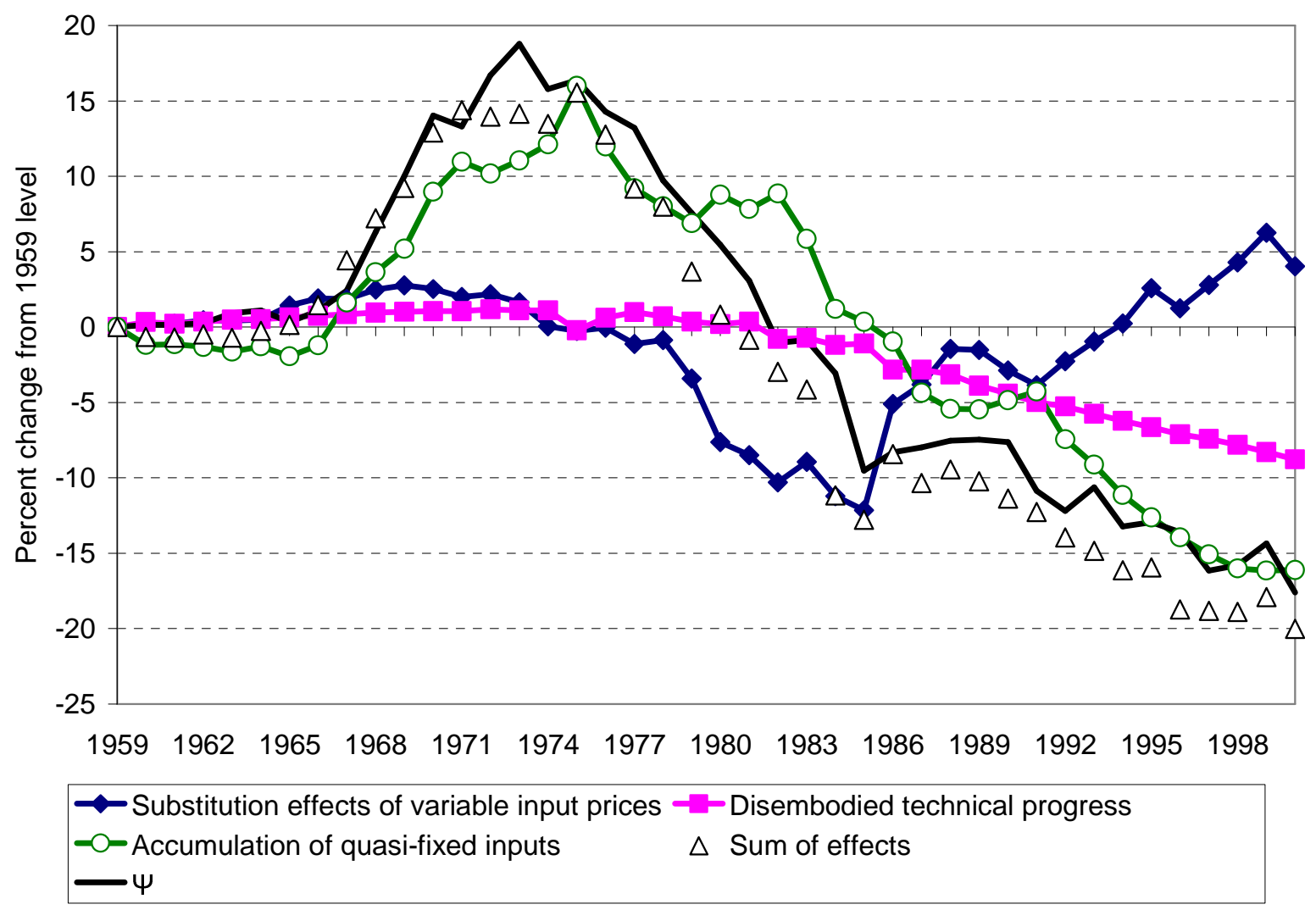


Figure 6. Aggregate Impacts of Variable Input Prices, 1959-2000

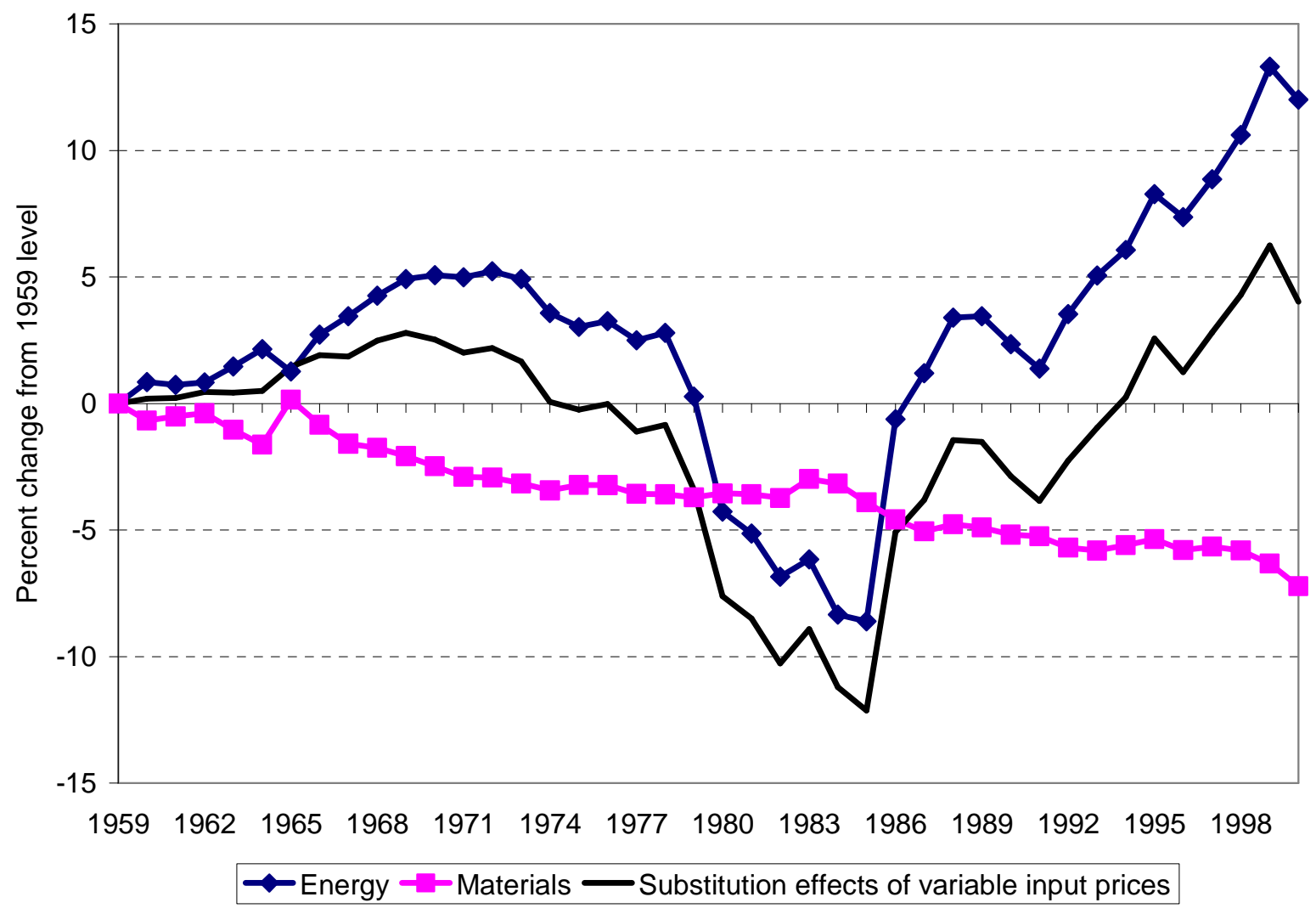


Figure 7. Aggregate Impacts of Exogenous and Induced Technical Progress, 1959-2000

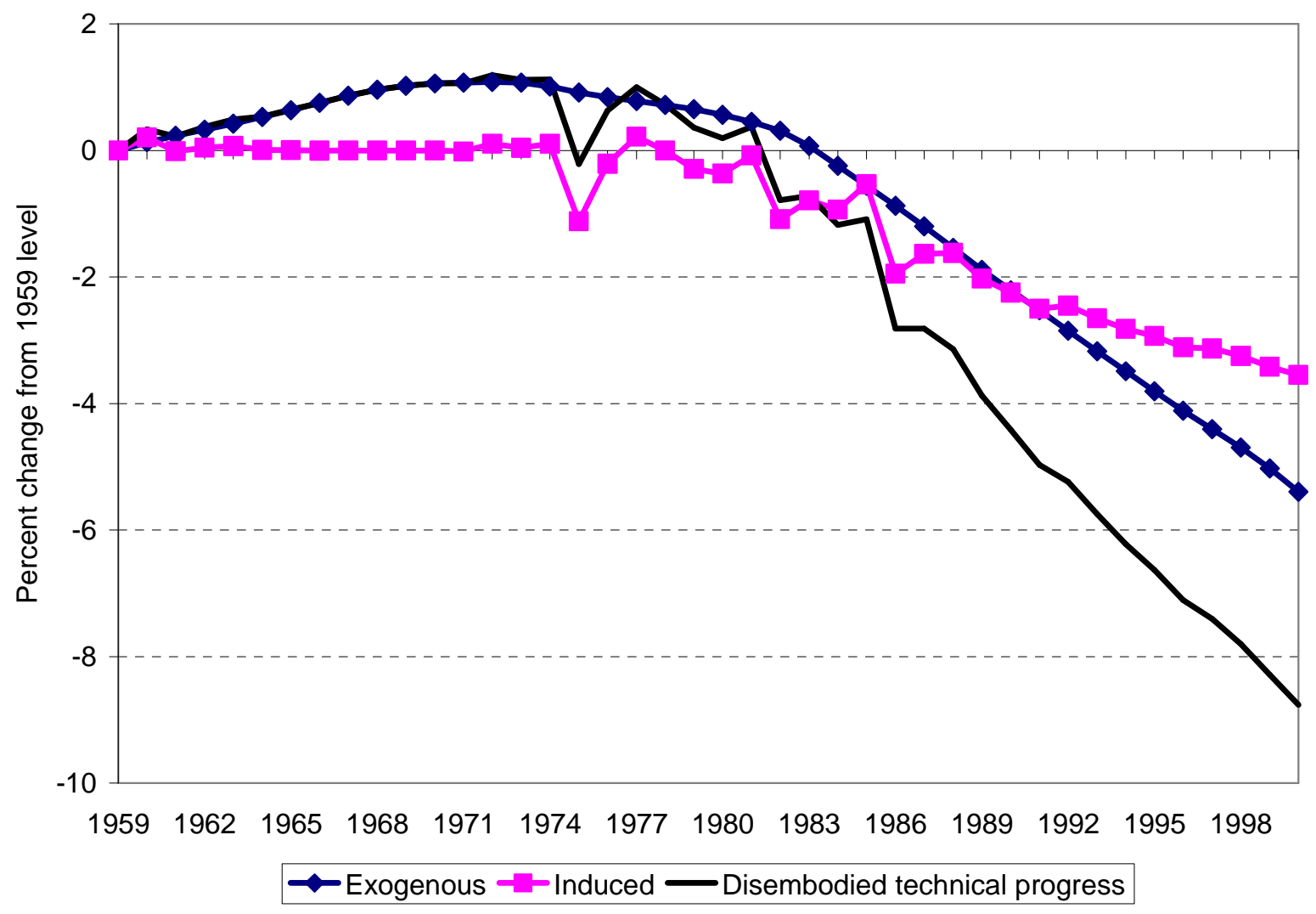


Figure 8. Aggregate Impacts of Quasi-Fixed Inputs, 1959-2000

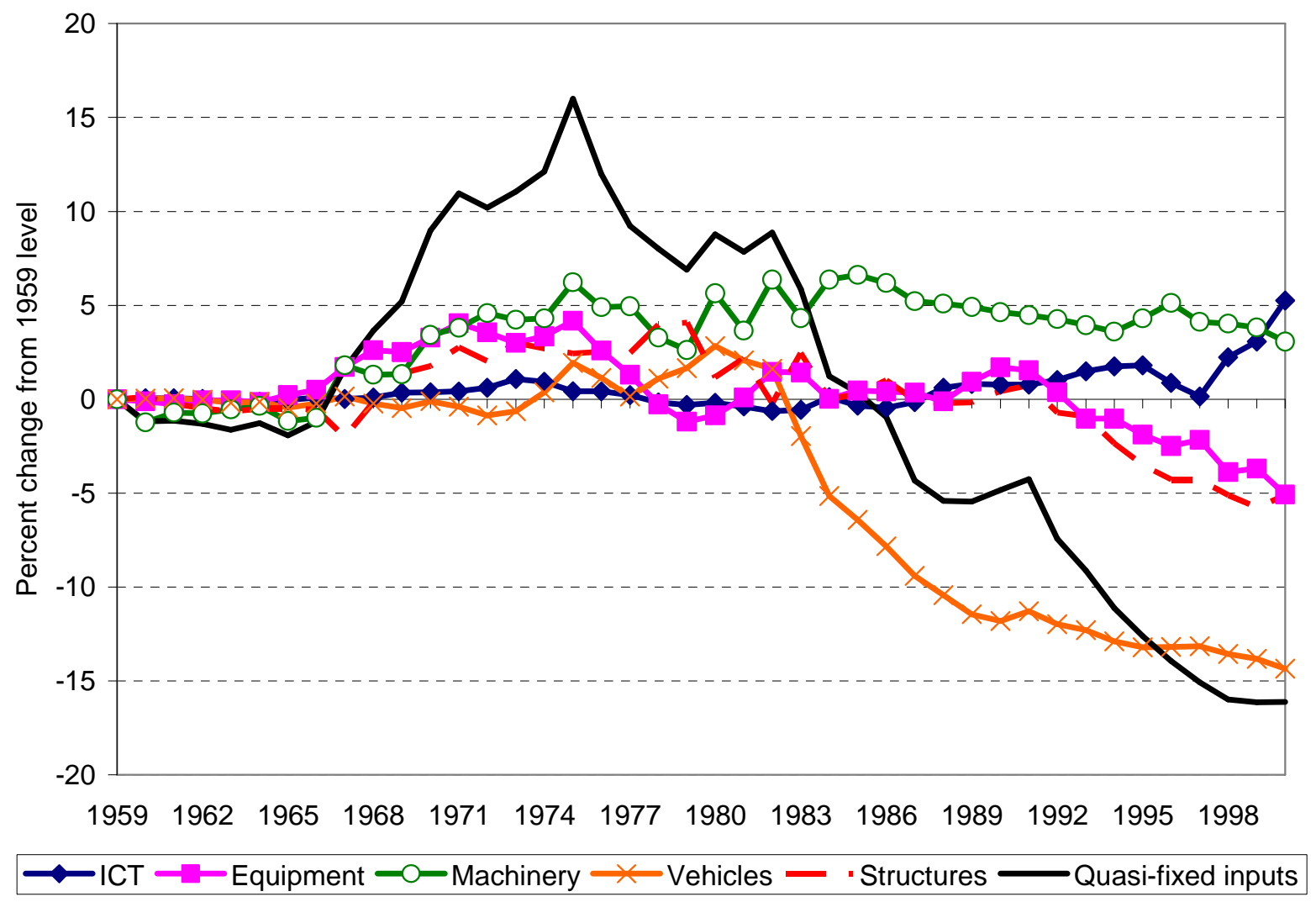

